Forthcoming in Evolution \& Human Behavior

\title{
Cross-cultural, developmental psychology: Integrating approaches and key insights
}

\author{
Dorsa Amir ${ }^{1}$, Katherine McAuliffe ${ }^{1}$
}

1. Boston College, Department of Psychology, 275 Beacon Street, Chestnut Hill, MA 02467, USA

*Corresponding author: Dorsa Amir, dorsa.amir@bc.edu

This research did not receive any specific grant from funding agencies in the public, commercial, or not-for-profit sectors. 


\begin{abstract}
:
Like psychology more broadly, developmental psychology has long suffered from a narrow focus on children from WEIRD societies-or those that are Western, Educated, Industrialized, Rich, and Democratic. In this review, we discuss how developmental scientists have sought to correct this bias through two complementary approaches: one centered on detailed, ethnographic investigations of child development within populations (increasing the depth of our understanding) and one focused on larger, multi-site studies that test children on standardized tasks across populations (increasing breadth). We review key papers from each of these approaches, describe how they are currently practiced, and discuss their strengths and weaknesses. Next, we highlight exemplary papers from the adult literature that offer useful insights, namely the importance of formal modeling and a greater focus on studying variation at multiple levels of analysis. We end by outlining best practices for future waves of cross-cultural, developmental science. Overall, we argue that a more integrated perspective, combining the strengths of the breadth \& depth approaches, can help better elucidate the developmental origins of human behavioral diversity.
\end{abstract}

Keywords: development, cross-cultural psychology, developmental psychology, WEIRD 


\section{Introduction}

In the now-seminal paper titled "The weirdest people in the world?", evolutionary anthropologist Joseph Henrich and colleagues highlighted a systematic bias in behavioral science that favored participants from WEIRD societies — or those that are Western, Educated, Industrialized, Rich, and Democratic (2010). In a review of studies across the psychological sciences, the authors found that $96 \%$ of participants were from WEIRD societies. In addition to being a poor proxy for the average human, representing just $12 \%$ of the world's population, the majority of samples were also coming from a limited sub-population within each country, strongly favoring undergraduate students (Henrich et al., 2010). In the ten years since its publication, "The weirdest people in the world?" has had a large impact on discourse in the behavioral sciences. While its more explicit impact on sampling practices in psychology is still under dispute (Rad et al., 2018), the paper brought a significant amount of renewed attention to the utility of cross-cultural work, catalyzing a new wave of standardized, multi-site investigations into human behavior.

While the WEIRD sampling bias is typically referenced in discussions of adult psychology, this persistent bias is also found in the field of developmental psychology. Despite the fact that there is substantial variation in fundamental aspects of child development across populations (Bornstein, 2013; Corsaro, 1996; Kruger \& Tomasello, 1996; Miller \& Goodnow, 1995; Nielsen et al., 2017), the vast majority of the work being done in developmental science also suffers from a strong sampling bias. In a review of articles in high impact-factor developmental journals, Nielsen and colleagues found a bias of similar magnitude to the one in the adult literature with over $91 \%$ of participants in 2008 coming from WEIRD societies (2017). In addition to a near-exclusive focus on Western samples, developmental science is also highly skewed toward certain subpopulations within the West, namely participants from White, middle-class, suburban communities (Rowley \& Camacho, 2015).

This extreme bias in developmental psychology samples is problematic as it may be impeding our understanding of the roots of human behavioral diversity. Early life is a particularly important period of behavioral flexibility with early experiences often shaping adult outcomes in consequential ways (Carlson, 2017; Kuijper et al., 2019). Further, an understanding of proximate causation in general-such as the role of the environment in shaping behavior-is incomplete without considering ontogeny (Tinbergen, 1963). An ontogenetic perspective allows us to extract 
valuable information about the stability, flexibility, heritability, and structure of behaviors (Liebal \& Haun, 2018). When coupled with a cross-cultural approach, it is even more useful in that it can help us assess more or less fundamental aspects of human behavior and identify the domains in which culture can penetrate cognition (Nielsen \& Haun, 2016). Indeed, one of the most useful contributions of anthropology to the study of human cognition-and the reason it was originally considered a core discipline of cognitive science (Boden, 2008)-is its ability to sample behavior across diverse contexts in ways that can help us reverse engineer the parameters and functions of cognitive processes. In these ways, anthropology can provide a natural experiment laboratory to help us better understand human development.

As currently practiced, cross-cultural work in both adult and developmental research frequently favors one of two approaches: one focused on depth - which often relies on detailed, deeply contextualized ethnographic data, usually from one society-and an approach focused on breadth-which relies more on experimental data from standardized tasks deployed across many different societies (see Figure 1 for a conceptual diagram and summary of these approaches). We consider these two approaches to be complementary, each with their own strengths and weaknesses. We are also aware that these are rough distinctions - much research does not clearly fall into one approach or satisfy all the criteria we have listed - but we still believe these generalizations are helpful for crystallizing a general structure of the history of cross-cultural, developmental research, as practiced. As the majority of cross-cultural work thus far has focused on finding or documenting universals rather than attempting to explain observed variability (Gurven, 2018), we believe a deeper integration of these two approaches can help move the field of cross-cultural developmental psychology forward and generate novel and important insights about human development. 


\section{The breadth approach}

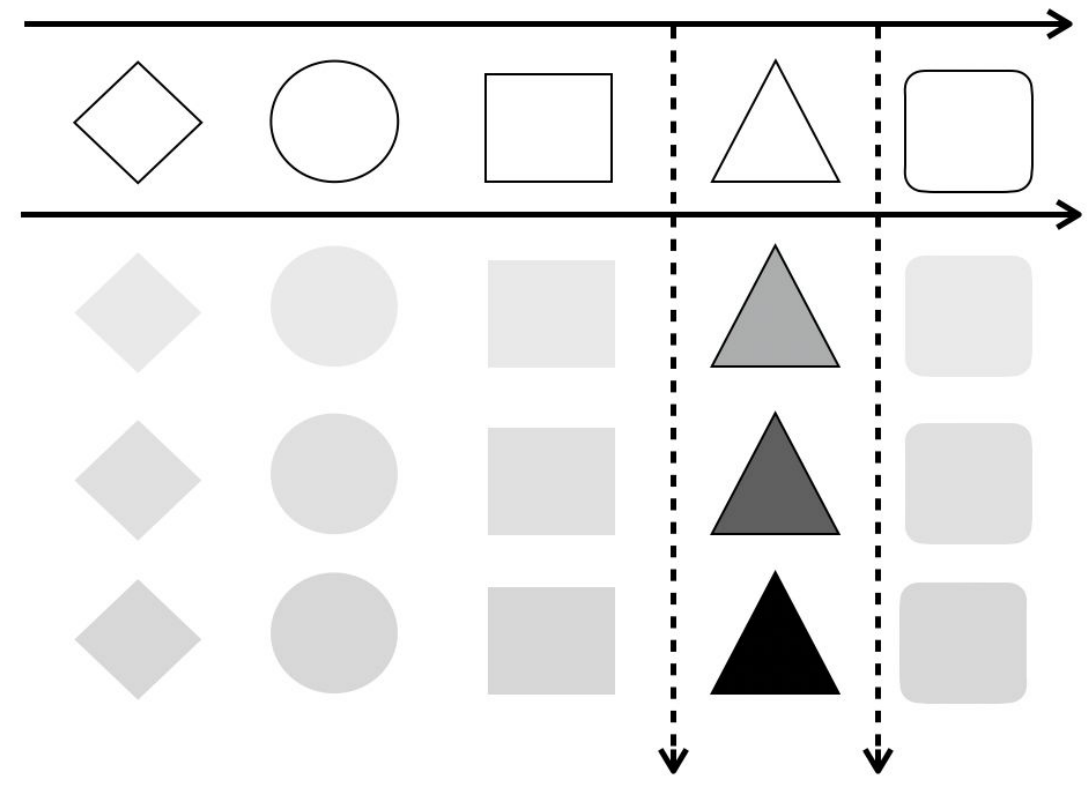

The depth approach

\section{Depth}

- Typically anthropology

- Largely focused on one society

- Can provide rich contextual information through ethnography

- Observational \& survey data

- Can help generate theories of causal relationships

\section{Breadth}

- Typically psychology

- Encompasses multiple societies

- Can better capture behavioral diversity across sites with standardized paradigms

- Experimental data

- Can help test theories of causal relationships

Figure 1: A conceptual diagram representing the depth and breadth approaches. (Top) Shapes can represent different societies or populations. Depth of color abstractly represents depth of insight. (Bottom) Typical characteristics of the two approaches. 
In the next section of our review (Section 2), we begin by contextualizing development in an evolutionary framework and briefly describe how cross-cultural, developmental data can provide insights into larger, evolutionary questions. In Section 3, we provide a review of the theoretical frameworks commonly used to situate child development in cultural context. We then highlight work focused on increasing depth of inquiry through detailed ethnographic studies, often centered on a single society, and work centered on increasing breadth of inquiry through multi-site studies that employ standardized experimental tasks. We end this section with a classic case study that shows how these complementary approaches can be fruitfully combined to provide rich, contextualized accounts of cultural variation in development. In Section 4, we review several important directions that cross-cultural work with adults has taken, and discuss why these developments have been instrumental in helping us better identify both the patterns and sources of human variation. In Section 5, we showcase examples of recent work that show particular promise for the future of the field. To end, we offer key insights for future waves of cross-cultural, developmental work that can help us gain a deeper understanding of human cognition, more broadly.

\section{Development in evolutionary context}

Unlike other great apes, young humans are dependent on others for long periods of time after weaning, and exhibit a unique life history stage called childhood. Fossil evidence tracking features such as the eruption of first, second, and third molars suggests that the length of this life history stage has more than doubled in the last 4 million years (Gibbons, 2008). Why did this extended period of development evolve? One functional explanation for this change is that a long period of development gave humans more time to learn the increasingly sophisticated knowledge required to be a successful adult. Humans have a unique challenge: in addition to learning about the world through direct experience with the environment, we also learn tremendous amounts of information indirectly through complex, cultural transmission. Further, we inhabit virtually every ecology on the planet, from the Arctic to the Amazon, living across environments that pose vastly different challenges and may promote different behaviors to aid fitness.

While development is undoubtedly a product of a complex interplay between ecological and cultural factors - after all, there is no ecology- or culture-free human - different views 
represented in the existing literature place different weights on these underlying factors. Drawing on evolutionary theory and behavioral ecology, one diverse school of thought has focused relatively more on an individual's experience of various environmental inputs, with predictions sometimes centered around adaptive phenotypic plasticity — or the ability of an organism to tailor development to environmental conditions (Frankenhuis \& Panchanathan, 2011; West-Eberhard, 2003). These research programs typically focus on the role of early environmental features — such as extrinsic mortality rate - in shaping behavioral outcomes - such as time preferences (Frankenhuis et al., 2016) or health behaviors (Nettle, Coall, et al., 2011). Some have argued, for instance, that experiences in early life, such as adversity, provide a 'weather forecast' of environmental conditions in adulthood; thus, it is adaptive for an individual to develop phenotypes that are suited for these types of environmental conditions (Bateson et al., 2004; Nettle et al., 2013). In other words, variation in behavioral outcomes, such as preferences, may arise from facultative or evoked responses to differing socioecological cues. These broader relationships at the ultimate level are sometimes linked to complementary proximate mechanisms from life history theory - such as differential energy allocation (Del Giudice et al., 2016) - or from psychology — such as changes in motivational states (Pepper \& Nettle, 2017). An empirical, developmental example of this type of framework's predictions comes from Safra and colleagues, who hypothesized that the harshness of a child's neighborhood would predict their prosocial behavior in an experimental game (Safra et al., 2016). Using a version of the Dictator Game with children in Romania, the researchers found that children living in harsh neighborhoods - i.e. those in the low income neighborhood - acted less prosocially toward strangers than children in the less harsh, higher-income neighborhood. These patterns mirror those found among adults in similar economic conditions (Piff et al., 2010; Nettle, Colléony, et al., 2011; Amir et al., 2018). In frameworks such as these, development is important as a time for increased sensitivity to environmental cues and developmental research in this area tends to exploit variation in these cues as natural experiments to determine downstream behavioral consequences.

A different, but - in our view, largely compatible - perspective, is one stemming from culture-gene coevolutionary (CGC) theory (reviewed in depth in (Richerson \& Boyd, 2005)). Like the adaptive phenotypic plasticity view detailed above, the CGC approach also offers a rich perspective on child development, but focuses relatively more on the role of cultural transmission in early life. 
Drawing on pioneering work in social learning theory (Bandura \& Walters, 1977; Rosenthal \& Zimmerman, 1978), proponents of this type of framework see development as a time for intense and selective social learning (Brosseau-Liard et al., 2013), and tend to focus more on variation in cultural norms and their internalization as the driving force of behavioral variation across societies (Chudek \& Henrich, 2011). Here, cultural norms are behavioral heuristics that individuals tend to follow when there are (1) a large enough number of community members that conform to it themselves - known as the "empirical expectation" - and when there are (2) a large enough number of community members that expect the individual to conform to it, too - otherwise known as the "normative expectation" (Bicchieri, 2016; House et al., 2019). Given the large amount of cultural models available to children and selective pressure to reliably distinguish better from worse cultural models (Brosseau-Liard et al., 2013), CGC theorists have focused much of their attention on identifying and testing biases in children's social learning, and probing mechanisms such as children's capacities for innovation and imitation (Legare et al., 2015; Legare \& Nielsen, 2015). Empirical work supports many of the predictions from this framework, with researchers finding evidence for children's selective learning from models that are perceived as more skilled (Sobel \& Corriveau, 2010), more experienced (Rakoczy et al., 2010), or more successful (Birch et al., 2008), among other traits. These investigations have also been extended to children in non-WEIRD populations, such as coastal villagers in Vanuatu( Clegg \& Legare, 2016) and BaYaka foragers in Congo (Boyette \& Hewlett, 2017; Salali et al., 2019). Proponents of the CGC view often suggest that early propensities for cultural learning are likely to be equivalent across all populations (Legare \& Harris, 2016) - for instance, that there is a universal norm psychology (House et al., 2019) - and that these shared propensities then interact with variable cultural norms across societies to produce variable behavioral outputs.

Cross-cultural developmental work is a useful tool for testing the predictions of these and other frameworks. Through selective sampling of various ecological and cultural features of interest (e.g. predictability of energetic resources or the prevalence of adult-to-child cultural transmission), researchers can gain greater insight into how these features may influence children's behaviors in systematic ways. Of most relevance to evolutionary theorists, careful cross-cultural work can contribute to distinguishing which features of our psychology and behavior are more or less sensitive to cultural input. While historically, researchers have sometimes used the 
term "universals" to refer to core mental attributes shared by humans everywhere (Norenzayan \& Heine, 2005), we prefer to co-opt Barbara Rogoff's use of the term "regularities" (2003).

Cross-cultural, developmental comparisons can help us track and measure regularities in children's behaviors and developmental trajectories across diverse environments. For instance, rejecting an allocation where you receive less than another person seems to appear with regularity in children across societies (Blake et al., 2015, discussed in greater detail in Section 3.2.1). On its own, these data from a handful of societies cannot irrevocably demonstrate that aversion to having less than another person is universal, but the regularity in its appearance can lead to new research questions. For instance, can the roots of this form of aversion be traced phylogenetically (McAuliffe \& Santos, 2018)? Can formal models of cooperative interactions favor inequity aversion (Fowler et al., 2005)? Taken together, converging lines of evidence appear to support the claim that this form of aversion can be a favorable strategy that arises with some regularity across diverse contexts. In this way, as one piece of a bigger puzzle, cross-cultural, developmental studies can help contribute to larger evolutionary and theoretical debates about human behavior.

\section{Cultural influences on development}

In this section of our review, we provide a general overview of theoretical, observational, and empirical approaches to studying how culture shapes child development. In Section 3.1, we discuss commonly-used theoretical frameworks that situate child development in cultural context and identify causal pathways of importance. In Section 3.2, we review recent work that has principally focused on ethnographic approaches and single-society analyses to provide depth of insight into child development within different societies. In Section 3.3, we review examples of investigations that have employed standardized tasks, often across multiple sites, to provide insight into the breadth of cross-cultural variation in child development. We next dig deeper into the breadth approach, discussing common ways of making sense of cross-cultural variation in development. We then review oft-used dichotomies and distinctions for cross-societal comparisons - such as WEIRD vs. non-WEIRD and individualistic vs. collectivist societies - and discuss the need to replace these distinctions with newer frameworks that are better grounded in theory. We end by highlighting a famous case study that integrates the strengths of the depth and 
breadth approaches through a standardized program that blends theoretical frameworks with ethnographically rich data from multiple, diverse societies (Section 3.4).

\subsection{Theoretical frameworks and causal pathways}

There is widespread appreciation in developmental psychology that ontogeny involves an interplay between biological, ecological and cultural factors (Callaghan et al., 2011; Greenfield et al., 2003). While approaches to understanding cultural influences on development differ in terms of the emphasis they place on different factors - for instance, cultural values and learning environments (see Greenfield et al, 2003 for a review) - they are united in a commitment to understanding the causal pathways through which culture affects the developing child. Indeed, there exist a plethora of models in both psychology and anthropology to this end. These include, but are not limited to, Bronfenbrenner's ecological systems model (Bronfenbrenner, 1994), the Whiting model of psychocultural research (J. Whiting, 1977), Vygotsky's sociocultural-historical theory (Vygotsky, 1980), Harkness \& Super's developmental niche model (Harkness \& Super, 1994), Weisner's ecocultural model (Weisner, 2002), Rogoff's transformation of participation approach (Rogoff, 2003), Keller's ecocultural model of child development (Keller, 2007), and later, Worthman's bio-ecocultural model of child development (Worthman, 2010).

A general feature of these models is that they all seek in some way to contextualize child development as a dialogue between the individual and the various social, ecological, and cultural inputs they experience. The Harkness and Super model, for instance, is concerned with three components: the physical and social settings in which the child lives, child-rearing and childcare customs, and the psychology of the caretakers (Super \& Harkness, 1986). The authors, and others, have leveraged this framework to assess how parents' ethnotheories about child development help shape practices, such as daily infant schedules (Super et al., 1996), and how these practices in turn influence child outcomes, such as patterns of play and social interaction (Parmar et al., 2004). Similarly, Bronfenbrenner's ecological systems model, arguably the most widely known theoretical framework in development (Vélez-Agosto et al., 2017), provides a guide for examining how the immediate internal and external environments children inhabit shape their development, with particular attention paid to individual differences, like temperament, and the ever-changing nature of these pathways across time (Bronfenbrenner, 1994). This framework has been utilized to 
examine a wide range of behaviors. For instance, Hong and Espelage used Bronfenbrenner's framework to examine bullying and peer victimization among youth in the United States, expanding out to assess how microsystems like parent-youth relationships, exosystems like exposure to media violence, and macrosystems such as religion all contributed to children's behaviors and beliefs (Hong \& Espelage, 2012).

Albeit theoretically and sometimes empirically useful, the utility of these models - and Bonfenbrenner's bioecological model, in particular - is challenged by conceptual confusions, such as what "culture" actually is (Vélez-Agosto et al., 2017). In Bonfenbrenner's model, for instance, the child sits within concentric spheres of cultural influence, with macro- and micro-systems alike exerting influence on their development. However, some have argued that the separation of the individual and their culture is misguided (Rogoff, 2003), as culture is not separate; rather, it is a product of human activity (Markus \& Kitayama, 2010). Indeed, Barbara Rogoff's "transformation as participation" approach explicitly considers development as a continuous process through which people transform through participating in culture, and their participation in turn transforms culture itself (Rogoff, 2003). Relatedly, Rogoff further argues that the distinction made in some frameworks between biology and culture is similarly misguided, as biology and culture are "not alternative influences but inseparable aspects of a system within which individuals develop" (Rogoff, 1990). We agree with this interpretation, and argue that newer iterations of these frameworks - namely Heidi Keller's ecocultural model (2010) and Carol Worthman's bio-ecocultural model of child development (2010) — are the most current and integrative of these attempts to situate development in both cultural and biological context. However, while these overarching frameworks, and especially those integrated with evolutionary theory, can be helpful in providing a broad overview of causal pathways, we believe these frameworks - and theory-building in general - can be strengthened through the integration of formal modeling (see Section 4.1 for a discussion of these topics).

\subsection{Depth: Ethnographic approaches \& single-culture analyses}

The ethnographic study of child development has its roots in the field of academic anthropology (LeVine, 2007; LeVine et al., 2008) and has typically focused on increasing our depth of knowledge by situating child development within the larger sociocultural environment in which it 
occurs. Anthropologist Franz Boas (1911), his student Margaret Mead (1928), and Bronisław Malinowski (1929) were among the first to suggest the importance of the cultural environment in shaping development and cast doubt on the idea that the behavior of children in the West was necessarily generalizable to other contexts. These early ethnographies, such as Meyer Fortes's work among the Tallensi children of Ghana (1938), involved months, and often years, of immersive fieldwork and culminated in intimate ethnographies that embedded children's lives into the complex cultures in which they took place. The majority of ethnographic work on child development in the early zoth century was focused on describing one cultural group in detail, such as the Hopi (Dennis, 1940), the Navajo (Leighton \& Kluckhohn, 1947), the Tikopia (Raymond, 1936), and indigenous communities in New Guinea (Hogbin, 1946) and Manam (Wedgwood, 1938). A few notable exceptions that examined children's behavior across multiple populations are Ruth Benedict's survey into child socialization (1938) which suggested that the transition to adulthood in Western societies is more discontinuous than in "traditional" societies, and the work of Barry, Bacon, and Child, which suggested that adults in agricultural societies are more likely to assign chores to children than those in foraging societies (1959).

As psychological methods and ideas began to gain more traction in scientific discourse, subsequent waves of ethnographic work focused on assessing the utility of psychological theories — such as neo-Freudian psychoanalysis (DuBois, 1944; Kardiner, 1939; Kardiner et al., 1945; Roheim, 1936) and Piagetian cognitive development (Bruner et al., 1966; Cole et al., 1971; Dasen, 1972; Dawson, 1967; Price-Williams et al., 1969) - among children of diverse societies. The latter half of the 2oth century brought with it a more modern brand of ethnography, which frequently involved the quantification of behavioral observations. These careful, observational studies fundamentally reshaped our understanding of developmental variation. For instance, while long bouts of infant crying were (and still are) common in WEIRD societies, the generalization of that pattern outside of the West was thrown into question by pioneering work on !Kung infant behavior. Through extensive observational fieldwork, anthropologists demonstrated that !Kung infants cried far less than Dutch infants, as they were responded to quickly and reliably by caregivers (Barr et al., 1991; Konner, 1972). Similarly, while WEIRD parenting culture is often focused on developmental milestones and trajectories such as the age at which an infant starts walking, observational work on early mobility across societies found evidence for substantial variation in child development, 
linked to cultural practices. For instance, Ache infants in Amazonian Paraguay, who are actively dissuaded from learning to walk due primarily to safety concerns, are delayed on motor development up to a year when compared to U.S. American infants (Kaplan \& Dove, 1987). Conversely, !Kung San infants, who are encouraged to walk from early on in development and held in vertical postures by parents, displayed earlier and more advanced motor development when compared to U.S. American infants (Konner, 1976). These careful, observational methods have also been leveraged to study a wide variety of behaviors in development such as the length of infants' vocalizations (Chisholm, 1978), the percentage of time spent with various caregivers (Tronick et al., 1987), the amount of time spent engaged in play (Gaskins, 2000), foraging (Hawkes et al., 1995), or at work (R. D. Lee \& Kramer, 2002), among other variables. Observational studies such as these, and the many that have followed, help bolster our understanding of child development by providing ecologically valid measures of relevant behaviors in the environments within which they occur. Additionally, observational data are less susceptible to biases associated with self-reports, such as socially desirable responding (Bornstein et al., 2015).

Despite the growing body of observational work examining child development, some scholars have argued that ethnographic documentation is not enough to constitute an anthropology of childhood on its own (Hirschfeld, 2002; LeVine, 2007). That is, while single-culture studies bring depth to our understanding of child development, further theory-building and cross-cultural comparison are necessary to create frameworks with greater explanatory power (LeVine, 2007). Some researchers have attempted to remedy this through meta-ethnographic approaches that compare child development across populations. Anthropologist Mel Konner's distillation of Hunter-Gatherer Childhoods (HGC) has been a model of particular import in this avenue of research (Konner, 2005). Comparing across the ethnographies of several hunter-gatherer societies such as the Hadza of Tanzania and the Martu of Australia, Konner indexed eleven aspects of infant- and childcare, such as frequency of nursing, mixed-age playgroups, and self-provisioning. This bird's-eye view of child development has allowed us to better see commonalities and differences between these diverse societies. For example, infants in all of the societies indexed are nursed frequently and for long durations of time -32 months on average (Konner, 2005). These results, coupled with data from other sources such as geochemical analyses of fossil hominid teeth (Austin et al., 2013), suggest that a long period of breastfeeding is a consistent and likely ancient 
feature of early human development. Ethnographic comparisons have also been fruitful in examining other aspects of early development, such as variation in learning strategies (Lancy et al., 2010), and parent-child relationships (Rohner, 1975; Trommsdorff \& Kornadt, 2003).

This meta-ethnographic approach has also been greatly aided by the Human Relations Area Files (HRAF), which continues to maintain its Cultural Information Archive, a corpus of nearly 800,000 pages of ethnographic work related to over 300 different cultural, ethnic, and religious groups around the world (Levinson, 1989). The technique of utilizing and comparing across archived ethnographic surveys has sometimes been called the holocultural approach (Munroe \& Gauvain, 2010), and was popularized by John W. M. Whiting and Irvin L. Child in their neo-Freudian analysis of child training and personality across cultural groups (J. W. Whiting \& Child, 1953). In the years that have followed, this approach led to a number of novel insights about the role of cultural systems in shaping child development. For instance, Carol and Melvin Ember used data HRAF to explore how differing levels of social and political integration influenced corporal punishment of children (2005). They find that societies with higher levels of social hierarchy and those in which nonrelative caretakers help raise children are more likely to engage in corporal punishment of children. In a similar meta-ethnographic study, Ember and Cunnar find that subsistence strategy is related to children's work: hunter-gatherer children do relatively less economic work than food producers, and, replicating Barry, Bacon, and Child's findings from 1957, they find that agricultural societies more commonly assign work to children than hunter-gatherers (2015). In a more recent paper utilizing this same approach, Sheina Lew-Levy and colleagues examined the mechanisms through which hunter-gatherer children learn subsistence skills across diverse ecologies (Lew-Levy et al., 2017). They find evidence of a consistent pattern across societies: learning begins in early infancy with children accompanying parents on foraging expeditions, continues in early and middle childhood largely in the context of mixed-age playgroups, and comes to maturation in adolescence when adults begin teaching children complex skills more directly.

However, while observational work has a number of strengths and has contributed greatly to our understanding of child development across societies, this work is in some ways restricted in its ability to identify causal models. This limitation can be ameliorated through the integration of more standardized, experimental approaches, which we outline in more detail below. 


\subsection{Breadth: Standardized approaches \& multi-culture analyses}

Building on early work that integrated multi-site approaches (Barry III et al., 1959; Benedict, 1938; Rogoff et al., 1975; Weisner et al., 1977), and more recently catalyzed by the model popularized by Henrich and others (Henrich et al., 2001, 2005, 2006), developmental psychologists have begun conducting more systematic, multi-site investigations into child development. Typically, work like this involves using a standardized task to test children's behavior on the exact same paradigm across multiple countries (Blake et al., 2015; House et al., 2013, 2019; Rochat, Dias, Guo, et al., 2009; Callaghan et al., 2005; Rochat, Dias, Guo Liping, et al., 2009; Neldner et al., 2019; Amir, Jordan, et al., 2019; House et al., 2019).

This standardized, experimental approach comes with a number of limitations. A primary limitation is the extent to which experimental games can generalize to naturalistic settings (Galizzi \& Navarro-Martinez, 2018; Gurven \& Winking, 2008; Hill \& Gurven, 2004; Levitt \& List, 2007). This issue, however, can be ameliorated through a careful consideration of how the experimental design - and the incentives it creates - fits into the larger decision-making environment the task takes place in. In cases where tasks effectively capture the incentive structure of real decisions, there tends to be convergence in behavior (Hardisty et al., 2013; Kröll \& Rustagi, 2017). For instance, Omra villagers treat the public goods game as they would their local tradition of community fundraising, known as harambee (Ensminger, 2004; Gurven \& Winking, 2008). To increase the match between lab-based behavior and actual decision-making, researchers should tailor their experimental designs to the cultural unit of study, using, for instance, local currency (Alvard, 2004) or culturally appropriate analogies (Hill \& Gurven, 2004). Other limitations of the experimental approach include cultural differences in the concepts and assumptions underlying the tasks (Rogoff, 2003), and the extent to which children's behavior is biased by other variables, such as task demands (Waterman \& Blades, 2011). While these problems are difficult to address, strategies such as back-translation, mixed method practices, and emically-shaped measurement tools can help ameliorate these issues (Norenzayan \& Heine, 2005).

Experimental studies, however, also offer a number of strengths, the most significant of which is their ability to manipulate and directly test causal pathways in ways that cross-sectional, observational data cannot. Additional strengths of experimental studies are that they typically involve the creation of a standardized protocol, often involving intuitive apparatuses, that decrease 
dependency on language, formal education, and numeracy. Where language is necessary, these tasks commonly incorporate comprehension checks to ensure that instructions are intelligible to children and adults across countries. Further, data generated through standardized tasks can be compared relatively more easily across different societies. And indeed, work like this has generated novel insight into the patterning and developmental trajectories of cross-societal variation. The standardized approach targeting breadth has been used to explore variation in many aspects of child development, including the emergence of fairness (Blake et al., 2015), generosity (Cowell et al., 2016), punishment (Rochat, Dias, Guo Liping, et al., 2009), subjective social status (Amir, Valeggia, et al., 2019), ownership (Rochat et al., 2014), theory of mind (Barrett et al., 2013; Callaghan et al., 2005), social learning (van Leeuwen et al., 2018) and risk and time preferences (Amir, Jordan, et al., 2019).

An exemplary case study of the utility of the multi-site approach is an investigation by House and colleagues (House et al., 2013) into the ontogeny of social behavior. Using an established forced-choice task (Fehr et al., 2008; Thompson et al., 1997), the authors explored the emergence of prosocial behavior in 3- to 14-year-old children across Aka, American, Fijian, Himba, Martu and Shuar societies. They presented children with a choice between a 1-1 offer, which would deliver one reward to the child and one reward to a peer (the other-regarding or 'prosocial' choice), and a 1-o offer, which would deliver one reward to the child and no reward to the peer (the self-regarding choice). In a second task, children were presented with a choice between the same prosocial offer (1-1) and a more advantageous selfish option (2-0). Compared to the first trials, in which the child gets one reward regardless of what they choose, the second trials are costly from the child's perspective: they either get two rewards or they must share with a peer. Findings from this study showed an interesting pattern of cross-cultural variation. When confronted with the first, non-costly choice, children across societies increasingly chose the prosocial (1-1) option with age and there was relative homogeneity in children's choices across sites. However, when confronted with the second, costly choice, children showed much more variation, suggesting that culture plays a more important role in shaping children's sharing behavior when costs are involved. Perhaps one of the most exciting results to come out of this paper was the finding that, by late childhood, children's choices began to converge with the choices of adults in their respective societies, helping 
elucidate the relevant developmental window during which local norms can exert considerable influence on prosocial behavior.

While the House et al. (2013) study provides a compelling example of why a multi-site approach is useful and how it can inform theories of cross-cultural development, additional work by members of the same research team demonstrates how experimental approaches can build upon and enrich these findings. Recently, the team built upon their previous work by using a similar paradigm to explore how cross-societal variation in norms and an emerging norm psychology interact to influence children's social behaviors, such as generosity (House et al., 2019) and third-party punishment (House et al., 2020). Critically, these studies involved an experimental manipulation: the authors showed children videos of an adult demonstrating a novel norm modeling, for instance, either selfish or generous behavior (House et al., 2019) - to explore how sensitivity to normative behavior shapes children's decision-making in these settings. In exploring prosocial behaviors, the authors find similarities in the timing and development of children's responsiveness to norms but variation in children's prosocial behavior, suggesting an underlying regularity in norm psychology that interacts with differing norms to produce differing decisions (House et al., 2019). In their work on third-party punishment, the authors find broadly similar patterns, such that the trajectories of children's punishment behavior suggest a shared, underlying psychology for responding to normative behavior. However, in the case of third-party punishment, it appears that children's previous knowledge of locally normative behavior may be in tension with novel norm information in influencing their decisions (House et al., 2020). These data - and these types of investigations in general - are particularly important for evolutionary, developmental science as they can help us better understand what features of early psychology are shared across societies (e.g. an underlying norm psychology) and what features are more sensitive to cultural input (e.g. the content of norms).

Additionally, from a methodological perspective, the investigations by House and colleagues show the utility of multiple waves of investigations that build on each other, beginning with a primary wave that first describes the behavioral landscape and patterns of variation. It is unfortunately common in the field for investigations to end after an initial wave, and for the authors to simply speculate about sources of observed variation in the discussion section. This trend has been exacerbated by an increased focus on the number of cultural sites in the sample, 
which, in some investigations, can rise past fifty (Wang et al., 2016). While documenting variation is a key first step in understanding the diversity of human behavior, we believe additional waves of data collection - ideally closely integrated with and informed by ethnographic data - are the necessary next steps for better explaining observed variation. Data from descriptive waves are important and relevant for generating novel hypotheses, but additional waves of data collection are also important, in that they can begin to test these predictions through carefully-designed experimental manipulations. Thus, we encourage cross-cultural investigators interested in increasing the explanatory depth of their work to begin thinking about their future projects in these multi-wave formats.

\subsubsection{On the use of population-level descriptors in cross-societal comparisons}

The studies reviewed above have contributed greatly to diversity in developmental sampling, helping correct the persistent WEIRD bias in the literature (Nielsen et al., 2017), and have pointed to rich cross-population variation in child development. However, the underlying causal explanations for variation still remain fairly elusive. The majority of current explanations for cross-cultural variations tend to be rooted in contrasts between high-level descriptors of different societies. These contrasts have primarily focused on dichotomies such as the distinction between WEIRD \& non-WEIRD societies and, particularly in psychology and sociology, the contrast between individualistic and collectivistic societies (Hofstede, 1984, 2011).

Contrast studies between WEIRD versus non-WEIRD populations have largely been conducted as tests of the generalizability of various findings. For instance, Schäfer and colleagues (2015) compared merit-based fairness judgments between children in Germany, $\neq$ Akhoe Haillom foragers in Namibia, and pastoralist Samburu in Kenya. They found that merit-based allocations mapped on roughly to the WEIRD / non-WEIRD divide, with German children allocating in accordance with merit while $\neq$ Akhoe Hail|lom and Samburu children were relatively more likely to distribute in accordance with equality. This finding was linked to the kinds of interactions common in these societies: for instance, frequent vs. infrequent interactions with strangers could influence whether merit or equality is relatively more valued in these WEIRD vs. non-WEIRD societies, respectively. Similarly, Blake and colleagues (2015) used the Inequity Game (Blake \& McAuliffe, 2011), a standardized task used to measure children's rejections of unfair allocations, to examine 
the development of fairness across seven societies. In this task, the experimenter uses an apparatus with tilting trays to test children's responses to different allocations of resources, some of which are equal (always 1-1; one for the actor and one for the recipient), and some of which are unequal. The direction of inequality varies between subjects, with the actor seeing either disadvantageous distributions (1-4; one for the actor and four for the recipient) or advantageous ones ( $4-1$; four for the actor and one for the recipient). In taking this task to diverse societies, the authors hypothesized that they would observe rejections of advantageous inequity - cases where the actor had more than the recipient - only in WEIRD societies (Canada and the USA), which are characterised by strong institutions of fairness, and that these rejections would emerge later in development. They also predicted that rejections of disadvantageous inequity — where the actor has less than the recipient - would be more common across societies and appear earlier in development. The data partially supported this hypothesis. Rejections of advantageous allocations were indeed observed in Canada and the USA but they were also seen in Uganda, a non-WEIRD society. Where advantageous inequity aversion was observed, it always emerged later in development than disadvantageous inequity aversion. This pattern of findings suggest that advantageous inequity aversion is likely shaped by local cultural norms later in development, and raises questions about the specific content of norms, given that the data did not pattern strictly along WEIRD/non-WEIRD lines as predicted. In contrast, rejections of disadvantageous allocations were observed earlier in development and across all seven societies, suggesting that this self-focused form of fairness (i.e., protecting oneself from unfairness) is a more foundational response in development (Figure 2). 

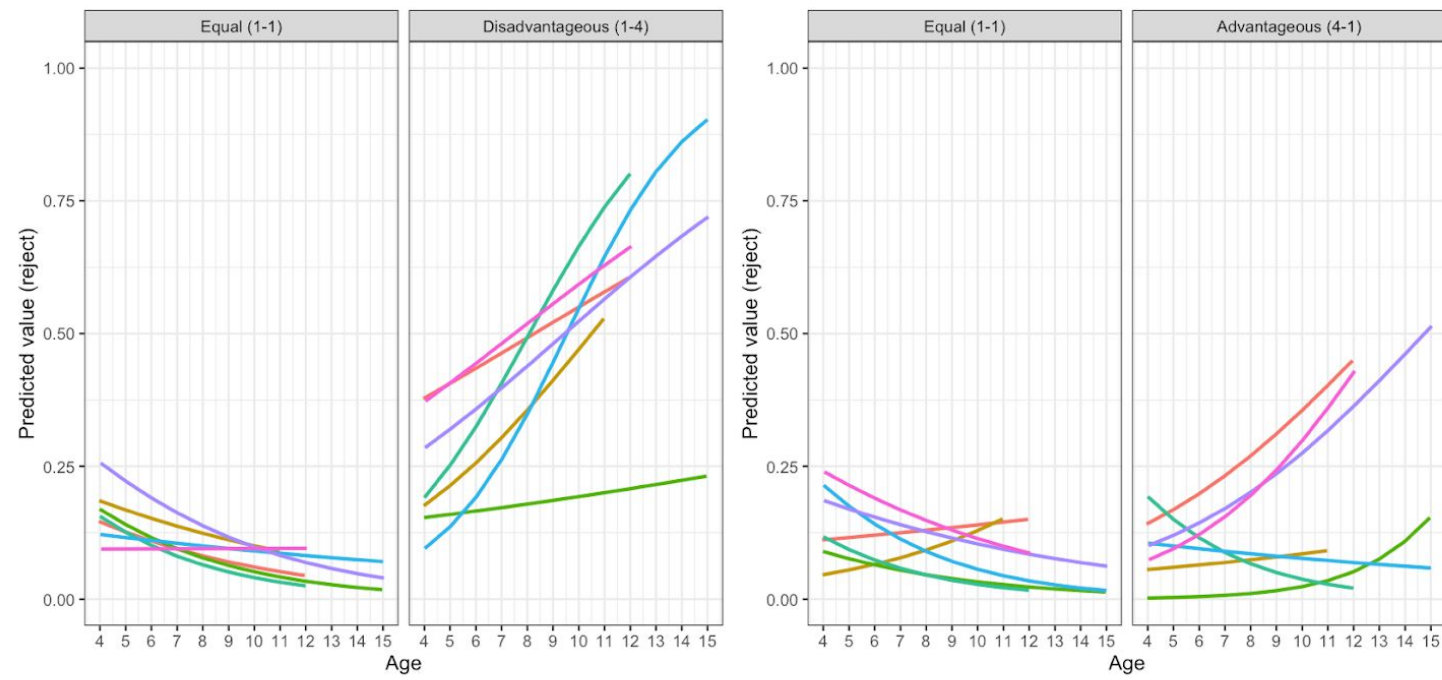

Figure 2: A visualization of the results from Blake, McAuliffe et al. 2015.

We believe the Blake investigation offers a number of interesting insights. First, it is descriptively true that the distinction between WEIRD and non-WEIRD societies has provided a heuristic which has served as a useful first pass for carving up existing variation. As a concept, it has also proved sufficiently simple and powerful to motivate new waves of work that seek to correct the massive bias in sampling. We see these as steps in the right direction. However, the WEIRD distinction, and certainly the acronym on its own, is severely limited in its explanatory power. That is, simply comparing WEIRD with non-WEIRD societies is not enough to elucidate causal pathways of behavioral development, and should not be the stopping point for cross-cultural research. Again, the Blake et al. paper serves as a useful example for illustrating both the benefits of a WEIRD/non-WEIRD approach — in that it catalyzes work with non-Western populations, better captures behavioral diversity, and provides a very rough heuristic for how societies may vary — but also its limitations, in that it is unclear within a simple, dichotomous framework what is causing the observed variation above.

In a similar vein, a large body of cross-cultural research has focused on contrasting more individualistic societies with more collectivist societies. Perhaps the most widely used index of this population-level feature is the Individualism vs. Collectivism (IDV) dimension from Hofstede's larger cultural dimensions framework (1984). The IDV dimension provides a measure of the degree 
to which people in a society are integrated into groups, with values such as autonomy and privacy held in higher regard among individualistic societies and values such as social harmony and loyalty valued more highly in collectivistic societies (Allik \& Realo, 2004; Bochner, 1994; Hofstede, 1984, 2011). The individualism versus collectivism contrast has been particularly influential in shaping cross-cultural work in developmental psychology (Chiu Loke et al., 2014; Dmytro et al., 2014;

Greenfield et al., 2003; Krassner et al., 2016). For instance, researchers have used the IDV dimension to explain why modesty behaviors vary across societies. This work has shown that young children in more individualistic societies are less likely to endorse modesty than children those in more collectivistic societies on surveys assessing children's judgments in response to vignettes (Genyue et al., 2011; Heyman et al., 2010; K. Lee et al., 1997, 2001). Across multi-site samples, the IDV dimension has also been used to examine preferences for equality versus equity in children. In a recent paper, Huppert and colleagues presented 4- to 11-year-old children across 13 societies with distributive justice games which measured their preferences for how resources ought to be shared across different contexts (Huppert et al., 2018), probing how sharing is driven by equality compared to equity (sharing based on merit, need or empathy). While a general shift from equality- to equity-based preferences emerged across societies, the team found that children from more individualistic societies showed an earlier shift towards equity-based preferences in the contexts of merit and need.

While the contrast between individualistic and collectivistic societies is relatively user-friendly, there are a number of overarching concerns with these types of frameworks, and with Hofstede's cultural dimensions, in particular (Ailon, 2008; Kitayama, 2002; Singh, 1990). Notably, McSweeney offers a number of critiques, arguing that small sample sizes in the underlying surveys used to construct the dimensions cannot be automatically generalized to the national level, and that fundamental assumptions underlying the work - such as the assumption that an average tendency is the average tendency - are all flawed (McSweeney, 2002). Further, some have argued that the dichotomous nature of the individualism/collectivism distinction is too reductionistic and simplistic to offer much insight (Killen \& Wainryb, 2000), and that both attitudes can coexist within a culture (Killen \& Wainryb, 2000) but simply be given different weights (Greenfield et al., 2003). These criticisms, and others, are not restricted to Hofstede's dimensions and can apply more generally to the use of other country-level indices in cross-societal 
comparisons, such as the Gini coefficient which provides a measure of population-level income inequality. For instance, while the Gini coefficient that can indeed be used to predict variation in behavior, such as people's preferences for redistribution (Kerr, 2014), it is also sensitive to a number of biases such as the small-sample bias - see (Deltas, 2003).

While popular, these national-level indices in general are further limited in their ability to explain variation in the behaviors of individuals. That is, while a country's collectivist attitudes, for example, can be correlated with individual performance on a task, we are still left with the question of why these attitudes vary in the first place and the pathways through which they shape individual behavior throughout the lifespan. More broadly, there are a number of inherent limitations to cross-cultural correlations of individual behavior with macro-level data, such as group-level indices. Some of these limitations are that (1) relationships at the aggregate level do not necessarily accurately represent individual-level processes, that (2) data points are non-independent and violate assumptions of inferential techniques in null hypothesis testing, and that (3) there exist differences in construct validity across groups that can lead to broader non-equivalencies in measurement (Pollet et al., 2014). The validity of assuming that patterns in individual behavior scale to group-level behavior is exacerbated by a phenomenon known as Simpson's Paradox, in which a trend found at the population level can actually reverse when evaluated at a subpopulation level (Kievit et al., 2013). Such is the case of economic risk preferences, in which country-level GDP per capita is related to more risk-aversion but household level income is related to more risk-tolerance (Bouchouicha \& Vieider, 2019). To combat these types of limitations, researchers could privilege longitudinal projects, focus on gathering data at multiple levels, and exercise more caution when drawing inferences about individual-level processes from group-level data (Pollet et al., 2014).

Further, researchers can focus more attention on developing new metrics that are not as vulnerable to these limitations. In recent years, researchers have made great strides in formulating novel ways to measure cultural distance. Notably, Muthukrishna and colleagues have developed a new metric to help researchers design, plan, and justify comparative psychological projects (2020). Based on a mathematical method originally intended to calculate the degree of genetic distance between two populations - called the Fixation Index or $F_{S T}$ - the team created a novel metric, called the Cultural $F_{S T}$ to calculate cultural distance from a large survey of cultural values across 
diverse societies. These methods are already gaining traction in studies of cross-cultural variation in the behavior of adults (Handley \& Mathew, 2020).

\subsection{Combining depth and breadth: The Six Cultures Study}

In practice, the logistics of conducting cross-cultural research can sometimes result in a trade-off between breadth and depth: it is challenging and time-intensive for one person or even one team to collect detailed ethnographic information across a wide range of societies. However, we believe there is much to be gained by combining and integrating the strengths of these two approaches. One notable and influential body of work in this fertile overlap is work on the emergence of social behavior by Beatrice and John Whiting (Edwards \& Whiting, 1988; B. B. Whiting \& Whiting, 1975), often referred to as the Six Cultures Study. The unprecedented and ambitious project had a series of interlocking parts. In collaboration with their field teams, the researchers first produced detailed, general ethnographies of children in six societies - in Kenya, Okinawa, India, the Philippines, Mexico, and the United States - which included descriptions of child-rearing and child life at the cultural level (B. B. Whiting, 1963; B. B. Whiting \& Whiting, 1975). Next, the teams worked with families in each of these communities, conducting structured interviews with mothers (Minturn \& Lambert, 1964). And finally, the field teams collected a large number of standardized observations of children's behavior, culminating in over 2,000 five-minute observations and nearly 10,000 coded interactions of approximately 134 children between the ages of three and eleven (B. B. Whiting \& Whiting, 1975).

Lamenting the fact that most existing cross-cultural examinations simply described differences as opposed to systematically exploring them, Whiting and Whiting used their corpus of data to address some of the most important questions in child development at the time, such as the effects of sex, age, birth order, and culture on social behavior. Across societies, the researchers identified a pair of dimensions - namely, the complexity of the socioeconomic system and the composition of the household - that predicted children's social behavior, for instance that children in what they termed 'less complex cultures' tended to be more nurturant-responsible (e.g. took greater care of younger siblings) than those in 'more complex cultures'. They also documented consistent sex differences in children, such that girls were more likely to seek help, while boys were more likely to seek attention and dominance. These early insights into the role of culture in 
children's socialization, and in particular into the development of prosocial behaviors, laid the groundwork for new waves of work seeking to unpack the concept of culture (for a review of the impact of culture on prosocial development, see de Guzman, Do, \& Kok, 2014).

In addition to these empirical insights, the Whitings also contributed a number of more general ideas to anthropology and psychology. In a review of their work and a discussion of their legacy, Pope Edwards and Bloch outline five ideas of particular importance: (1) the assumption that humankind is psychologically united, (2) the idea of a 'cultural learning environment', (3) the Whiting Model for psychocultural research, (4) the fruitful relationship between anthropology and psychology, and (5) the important role of mothers, in particular, as agents of social change (Pope Edwards \& Bloch, 2010). We refer the readers to Pope Edwards and Bloch's thorough review for a more detailed discussion of these topics and how they fare today, but will discuss one of these ideas here that we believe are of particular importance and relevance to future work. We believe an enduring lesson from the Six Cultures Study is the effectiveness of the Whiting Model for studying child development - a model of research that focuses on the causal roles of fundamental societal features, such as ecology and economy, on child training practices, which in turn lead to variation in adult behavior (Konner, 2010). The Whiting Model, though sometimes criticized for assuming an underlying direction of causality from the learning environment to the individual's development (Rogoff, 2003), still provided a major conceptual advance in understanding human development in particular, moving beyond the nature-nurture distinction to a focus on their interaction - and its assessment of human development from multiple levels of analysis (Worthman, 2010). In contrast to Bronfenbrenner's model, in which culture is an outer ring of influence, culture is infused throughout the major components of the Whiting Model, such as in maintenance systems like subsistence patterns and social structures (Vélez-Agosto et al., 2017). However, the Whiting Model has sometimes been criticized for not engaging deeply with the biological foundations of behavior and evolutionary theory (Keller, 2010). More recent iterations and expansions of the Whiting Model, such as Keller's ecocultural model of child development, go one step further in integrating the Whitings' proximate causal pathways with a broader, evolutionary framework that adds an ultimate perspective (Keller, 2010).

Methodologically, the Six Cultures study was trailblazing in several additional ways: (1) it combined both inter- and intra-population approaches, $(2)$ it explicitly challenged the assumption 
that children's behavior in Europe and the United States was generalizable to children across all societies, (3) it was an early adopter of collaborative research efforts, and (4) it utilized a wide range of complementary methods to study child development. The variety of data forms - such as direct field observations and historical ethnographies (Worthman, 2010) - integrated the strengths of the depth and breadth approaches outlined above in effective ways. These enduring lessons are still relevant and applicable to strengthening cross-cultural, developmental research. Indeed, decades after the Six Cultures study, Beatrice Whiting echoed these points in three takeaway messages for future work (Shweder, 1999). The first was a message to stay interdisciplinary, and the second an encouragement of collaboration between developmental psychology and anthropology. The third perhaps belongs in a footnote ${ }^{1}$.

Despite their clear and important contributions to the field of cross-cultural developmental science, the Whitings' contributions had arguably less impact on developmental studies than they may have deserved, though this may be field-specific. Robert LeVine, the Whitings' former student, argues that the projects' greatest long-term contribution was an increased focus on ethnography and naturalistic observations (LeVine, 2010). As we reviewed in section 3.1, these methodologies gained significant traction in the field of anthropology, contributing to a growing corpus of work on naturalistic, observational data on child development. While we can only speculate as to why this form of research has not become the norm in developmental psychology, it may be the case that logistical constraints such as coordinating a large, international team and/or the financial constraints of this type of work played a part - after all, the Six Cultures study involved a collaboration between half a dozen field teams and cost \$350,000 in 1954 - equivalent to about \$3.3 million in 2020 dollars (LeVine, 2010).

\section{Insights from adult work}

What can cross-cultural, developmental science learn from work in other fields? Here, we review exemplary work from the adult literature that can shed light on best practices. In short, the work reviewed in this section supports two key insights: explanatory power can be increased through (1) greater integration with strong theoretical and formal models and (2) an increased

\footnotetext{
1 "Number three: Americans are all hung-up about sex and can't tell the difference between eroticism and tactile touching. Those are her messages." (Shweder, 1999).
} 
focus on studying variation at multiple levels of analysis. Further, successful implementations of these insights frequently occur in collaborative, interdisciplinary research teams, which represent an important avenue for supporting reproducibility and theory-building in developmental science (Frank et al., 2017).

\subsection{The importance of good theory \& formal modeling}

While theoretical frameworks such as Keller's ecocultural model for child development can offer a bird's-eye view of causal pathways, we believe future work can be further strengthened by an integration of recent advances in theory-building outside of the developmental literature. In recent years, in conjunction with the larger movement toward replicability and transparency, a number of behavioral scientists have renewed arguments for strengthening our theoretical frameworks to improve our inferences (Gurven, 2018; Muthukrishna \& Henrich, 2019; Smaldino, 2019). Of the various frameworks, there are two of particular import for understanding human behavior: the theory of evolution and the computational theory of mind. The first of these posits that all traits, including cognitive processes, were shaped over time through evolutionary forces such as natural selection. The second posits that the mind itself is fundamentally a computational system whose primary function is information-processing. That is, understanding how the mind functions is a tractable problem that requires reverse engineering the computational processes that lead to behavioral outputs. Taken together - and sometimes referred to as the New Synthesis (Fodor, 2001) - these two theories suggest that the human mind is a naturally selected system of organs of computation (Pinker, 2005). Thus, an integrative perspective that incorporates tools from cognitive science with evolutionary biology can provide a rich theoretical framework from which to generate predictions (Brase, 2014). This is particularly useful in helping us identify the level of analysis that best fits our research questions. Therefore, starting with these first principles, effective theoretical models for understanding human behavior should be, as Muthukrishna and Henrich argue, evolutionarily plausible and frequently modeled using formal, computational tools to produce ultimate frameworks that deliver proximate predictions (Muthukrishna \& Henrich, 2019). Here, an ultimate framework is one that focuses on the evolutionary reasons why a trait might develop, while its proximate predictions outline how that functionality is achieved (Scott-Phillips et al., 2011). 
Formal modeling is a particularly useful tool in this endeavor. Here, we use "formal modeling" to broadly refer to models whose purpose is to formalize assumptions and relationships between variables, and not models used for statistical analysis. We are agnostic to the form this modeling can take (e.g. analytic versus agent-based modeling); we simply propose that these types of endeavors in general can help researchers clarify the assumptions underlying their theories and study their consequences. Formal models that integrate evolutionary and developmental theories can further help us explore the ultimate causes of various cognitive mechanisms and proffer insight into the proximate processes through which behavior is shaped (Farrell \& Lewandowsky, 2018; Frankenhuis \& Tiokhin, 2018; Frankenhuis \& Walasek, 2020; Hinton \& Nowlan, 1987). Formal modeling is a powerful, generative tool that can help us better predict how variation in environmental features - whether ecological, cultural, or both - can plausibly lead to systematic differences in behavioral outcomes, thus motivating waves of studies that can evaluate these predictions. In an ideal world, as Smaldino argues, strong theories, formal models, and measurements will interact in a "virtuous cycle" (2019) to produce greater explanatory power and inference. (And, as he succintly puts it, "Models are stupid and we need more of them" (2017)).

A number of investigations examining cross-cultural variation in behavior have used these theoretical frameworks and formal modeling in exemplary ways. The first of these is a series of related projects exploring the structure of personality across diverse contexts. The study of personality - or persistent patterns of behavior that are stable across time and contexts (Fleeson, 2001; Smaldino et al., 2019; Wood \& Denissen, 2014) - and the way in which it may be structured has long been of interest to psychologists. One common approach to studying personality structure is to statistically extract patterns of covariance into factors. This approach led to the famous "Big Five" model of personality, which organizes personality dimensions into five factors: openness to experience, conscientiousness, extraversion, agreeableness, and neuroticism (John et al., 2008). The Big Five is a robust factor structure with relatively high rates of stability across time and contexts. However, to date, the vast majority of work on personality structure has been conducted among WEIRD populations, limiting our ability to generalize the structure or make claims of cross-cultural universality - which some have claimed, nonetheless (McCrae \& Costa Jr, 1997). When a team led by anthropologist Michael Gurven explored personality structure in a non-WEIRD population - in this case, among a large sample of forager-horticulturalist Tsimane adults in 
Bolivia - they found weak support for the Five Factor model, instead finding that personality variation among the Tsimane displayed two, rather than five, principal factors (Gurven et al., 2013). To understand why this may be the case, the team pursued another interdisciplinary collaboration to explore the role of social complexity in shaping personality types. Integrating previous empirical work on personality structure with others suggesting behavioral flexibility in the face of variable socioecologies, the team built a simple model to explore how social complexity could lead to a greater diversity of social niches - or social and occupational roles within a society - thereby reinforcing a greater diversity of behavioral traits. The model provided a novel prediction: that individual trait variation should increase with niche diversity. The team then found support for this novel prediction in a large cross-cultural dataset, finding that greater socioecological complexity was indeed associated with more individual trait variation (Smaldino et al., 2019). This integrative process of bringing together existing data with formal models to produce novel predictions that are then empirically tested is a strong example of the "virtuous cycle" of replicable science (Smaldino, 2019) and represents a tractable approach for increasing the explanatory power of our research.

The growing body of work on cultural evolution is home to a large number of other exemplary investigations that blend formal models and empirical data to explain variability across cultural contexts. For instance, in an investigation exploring the roots of complex societies in the Old World, Turchin and colleagues built a cultural evolutionary model to predict the locations and time points at which the largest-scale complex societies should have arisen in human history given important geographical features, such as the ruggedness of a landscape, and the spread of military technologies, such as chariots and cavalry (Turchin et al., 2013). These model outputs were then tested, and fared well, against real, historical data. In another domain, Reali and her team (2018) modeled the relationship between population size and linguistic features such as grammatical difficulty and vocabulary size. Their cultural transmission simulations suggested that one primary cognitive constraint - ease of learning - could parsimoniously explain why an increase in population size can lead to both more grammatical simplicity and a larger vocabulary (Reali et al., 2018). These, and a growing number of other investigations in this fashion, exemplify the type of careful investigations that can increase explanatory power through an integration of strong theoretical frameworks, formal models, and empirical data. Of course, formal models of cognition 
are not at all new or radical in developmental science (see Shultz, 2003 and Mareschal \& Thomas, 2007 for comprehensive reviews); we simply argue there is much to be gained from applying these existing methods and perspectives to the study of cross-societal variation, in particular.

\subsection{The importance of studying variation at multiple levels of analysis}

While exploring how behavior varies across groups is a worthwhile pursuit in developmental science, increased attention to the forces that shape behavior within groups can greatly contribute to our understanding of developmental psychology. More generally, we argue that a more careful exploration of variation at multiple levels of analysis is critical for future work. This type of work can range from comparisons of individuals within communities to comparisons of communities within larger populations, and can involve varying cultural units, such as ethnic groups, countries, or religions. Though the WEIRD paper is often thought of as a call-to-arms for increasing cross-cultural work, another key finding in the paper was the persistent skew in sampling even within Western countries. The authors found that nearly $70 \%$ of American samples - and $80 \%$ of non-American samples - were composed of undergraduate students in psychology courses (Arnett, 2008; Henrich et al., 2010). Put another way, a randomly selected undergraduate student in the United States is more than 4,000 times more likely than a randomly selected person outside of the West to be a research participant (Henrich et al., 2010). This extreme bias in sampling is also present in developmental work (Nielsen et al., 2017), which is almost exclusively focused on samples of White, middle-class, suburban children (Rowley \& Camacho, 2015). Additionally, there is a tendency to treat small samples from different countries as uniform and homogenous entities, even though in most cases, there is more variation within groups than between groups (Lamba \& Mace, 2011; Realo \& Allik, 2002).

This gap in our knowledge suggests another important avenue for improving our explanatory and inferential power: increasing our focus on psychological variation at multiple levels of analysis and, more generally, identifying the appropriate cultural unit to fit our research questions (e.g. the national, community, or individual level, and so on). Often, this can be done by expanding out beyond convenience samples to so-called "inconvenient samples" which often include individuals living in urban, working class, and/or ethnically diverse subpopulations (Gurven, 2018). Interacting with diversity within countries, for instance, can provide key insights into the role 
the socioecological environment plays in shaping developmental processes and outcomes (Bang \& Medin, 2010; Legare \& Harris, 2016). Further, an integration of empirical work with the cultural history of the region - whether through ethnography (Gurven \& Winking, 2008; Keller, 2018) or social and economic history (Nunn, 2009; Schulz et al., 2019) - can help situate findings by providing cultural context and increasing interpretive power, or our "ability to understand individuals' experiences and behaviors in relation to their cultural contexts" (Brady et al., 2018). For example, a recent investigation by Schulz and colleagues explores the historical role of the Western Church in shaping modern psychological patterns (2019). They find that countries with a longer history of exposure to the Church or less intensive kinship are also places where individuals tend to be more fair, less conforming, and favor more individualism. These historical and cultural environmental shifts are similarly important for situating the ontogeny of behavior as they alter cultural values and learning environments, thus shifting developmental pathways (Greenfield, 2009).

To underscore the utility of studying variation at multiple levels of analysis, here we highlight a number of investigations in the adult literature that have effectively used a within-country approach to situate and explain behavioral variation. This approach is just one way, among many, to capitalize upon the rich psychological diversity found at multiple levels. In our first case study, lamenting the fact that psychology has produced a long list of East-West differences with no integrative theory to explain them, Talhelm and colleagues recently investigated psychological differences among subpopulations within China (Talhelm et al., 2014). The research team worked with over 1,000 participants across six sites to measure a battery of attitudes such as loyalty, cultural thought, and implicit individualism. The team then considered how well three theoretical frameworks of interest - the modernization theory, the pathogen prevalence theory, and the rice theory they put forward - fared in explaining observed variation in behavior. The modernization theory predicts that as societies become richer, more educated, and more capitalistic, they also become more individualistic and analytical. The pathogen prevalence theory predicts that high densities of pathogens in the environment make it more risky to deal with strangers, encouraging more insular and collectivist behaviors. And lastly, the rice theory predicts that differing subsistence styles require different behaviors - for instance, farming requires more functional interdependence than herding (Talhelm et al., 2014). Extending this framework further, 
the authors argue that two of the most common subsistence crops in the region - rice and wheat - require very different behaviors and have downstream consequences on broader, psychological attitudes. Rice paddies require intensive effort and large irrigation systems, which require high levels of cooperation to build and maintain. Indeed, these massive labor requirements often lead to the formation of cooperative labor exchanges (Bray, 1994). In contrast, wheat farming requires less effort and does not rely on irrigation, thereby reducing the need for large and intensive cooperative networks. When pitting the three theories against each other, the authors find that the rice theory is the best framework for explaining behavioral differences within China - people living in China's rice regions are more interdependent and holistic-thinking than those living in the Northern wheat-growing regions (Talhelm et al., 2014). This natural experiment within China suggests that subsistence strategy is an important factor in shaping behavior, and has implications for our understanding of variation across countries, as well. Talhelm's study also nicely demonstrates why national-level scores on dimensions such as individualism can be misleading: pigeonholing a country with over 1 billion people into one index score occludes the rich amount of diversity and variation within its borders.

This investigation is one of several noteworthy case studies from the adult literature that effectively utilizes within-country variation to explain variation in behavior. A second case study comes from Lowes and colleagues who explored how historical state centralization impacted cultural norms and behaviors among the Mongo people of Central Africa (Lowes et al., 2017). The team focused their work on the downstream consequences of the medieval Kuba Kingdom, which was formed in the 17th century and had many characteristics associated with modern states, such as a capital city, a professional bureaucracy, and extensive public goods provision. The boundaries of the kingdom were largely shaped by geographical barriers like rivers, such that villages of culturally homogenous Mongo peoples on opposing sides of rivers continue to exist in small chieftancies. Working with participants in villages with historical ties to the Kuba kingdom and those just outside of it, they find that those Kuba ancestry is correlated with more theft, more rule breaking, and more cheating behaviors in experimental settings, consistent with a historical pattern in which state formation crowds out internal norms of rule-following (Lowes et al., 2017). A third case study comes from Salali and Migliano who examined how socioeconomic transitions influence future discounting among Mbendjele BaYaka hunter-gatherers in the Republic of Congo 
(Salali \& Migliano, 2015). Capitalizing on natural variation in market integration, the authors worked with Mbendjele participants in three different camps with varying degrees of proximity to urban centers, in addition to a community of neighboring Bantu farmers. Participants were given a choice between one reward today or five rewards tomorrow to measure future discounting. The authors find that camp location is a significant predictor of patience - those living in less-integrated camps were much more willing to take one reward today, while those in camps nearer to cities and nearby Bantu farmers tended to be more patient. And in a final example of the strengths of a within-country approach, Nettle and colleagues examined variation in cooperative behaviors in Newcastle upon Tyne - a single city in the United Kingdom - and found neighborhood differences an order of magnitude larger than the largest differences in previous work between countries (Nettle, Colléony, et al., 2011; Safra et al., 2016).

In sum, these careful within-country studies can help move behavioral science from exploratory frameworks that largely chart variation to explanatory ones that identify key mechanisms that may be driving variation. They also underscore the importance of identifying the appropriate cultural unit for a research question and studying psychological variation at multiple levels of analysis.

\section{Key insights for cross-cultural, developmental work}

In the previous sections of this paper, we review the principal challenges and trade-offs in the study of cross-cultural, developmental psychology and identify key insights that can help strengthen future waves of work. Below, we summarize a number of these best practices to aid developmental scientists in future work (Box 1). These include big-picture changes - such as more careful integration with theoretical and formal models - along with more fine-grained adjustments — such as using standardized protocols with copious comprehension checks. 


\section{Key insights for future waves of cross-cultural, developmental psychology}

(1) Draw research questions from evolutionary plausible theoretical frameworks, considering both the ultimate and proximate levels of analysis

(2) When possible, use formal modeling to clarify assumptions and generate predictions

(3) Create standardized, reproducible protocols with extensive comprehension checks and low reliance on formal education and numeracy

(4) Seek out interdisciplinary collaborators from anthropology, psychology, economics, and related fields

(5) Engage in hypothesis-driven choice of populations based on the variables that are most relevant to the research question, even if they lead to so-called "inconvenient samples"

(6) Where possible, examine psychological variation at multiple levels of analysis, identifying natural experiments to test key predictions

(7) Provide information about and situate the work within the broader ethnographic context of the society, drawing upon observational data where possible

Box 1: Key insights for future waves of research in cross-cultural, developmental psychology

\subsection{Promising directions in cross-cultural developmental science}

In recent years, a number of studies in developmental science have integrated some or all of these practices in effective ways. Here we describe a subset of these studies, which in our view exemplify some of the most promising directions in which this field is moving.

Integrating theoretical and formal models within interdisciplinary collaborations (points 1, 2, and 4 in Box 1), the work of Frankenhuis and colleagues has been particularly successful in 
expanding our understanding of human development (Frankenhuis et al., 2013; Frankenhuis \& Del Giudice, 2012; Frankenhuis \& Fraley, 2016; Nettle et al., 2013; Stamps \& Frankenhuis, 2016). This approach has led to a number of insights across domains, such as a better understanding of early-life effects in development - cases where an input in early life has a more influential effect on the adult phenotype than the same input in later life (Fawcett \& Frankenhuis, 2015; Frankenhuis et al., 2019). Considering the conditions in which sensitive windows are expected to evolve, Fawcett and Frankenhuis proposed that key parameters are the availability, informativeness, and fitness benefits of informational cues, along with the fitness costs of plasticity itself (2015). Further, sensitive windows can be considered adaptive in environments with statistical properties such as reliable cues and high auto-correlation of environmental states (Frankenhuis et al., 2019). This theoretically-rich approach can thus equip developmental scientists with tractable predictions for how and when early-life effects might appear in development. (For a comprehensive overview of these and other formal models aiming to explain the evolution of sensitive periods in development, see W. E. Frankenhuis \& Walasek, 2020.)

Another interdisciplinary investigation of note, bringing together theoretical models of development with standardized, reproducible protocols and within-country analyses of inconvenience samples (points 1, 3, 4, 5, 6 and 7 in Box 1), our research team explored cross-cultural variation in risk and time preferences across children of diverse societies (Amir, Jordan, et al., 2019). Framing preferences not as innate characteristics, but rather as behavioral strategies shaped by the socioecological environment, we assessed the ontogeny of risk and time preferences across four societies. More specifically, our investigation explored the hypothesis that higher rates of market integration and related socioecological shifts would lead to greater risk-tolerance and future-orientation, drawing on literature suggesting that these preferences can be construed as uncertainty-sensitive behavioral strategies (Amir et al., 2018). Drawing on methodology from behavioral economics, we designed two child-friendly tasks to measure time preferences - how willing an individual was to wait until the next day for a greater reward — and risk preferences - how willing an individual was to choose an uncertain, but larger reward over a smaller, but certain reward. We then took these tasks to participants in the United States, Argentina, India, and hunter-horticulturalist Shuar children in the Ecuadorian Amazon. We found that children from the more-integrated communities in the USA, Argentina, and India were indeed 
more risk-tolerant and future-oriented than the less-integrated Shuar children. To examine whether these patterns held true within populations, we next conducted an assessment of risk and time preferences between Shuar children in more and less-integrated communities, and found the same pattern of results: Shuar children in peri-urban communities were more risk-tolerant and future-oriented than their counterparts in the remote, rainforest communities (Amir, Jordan, et al., 2019). This form of work, in which initial waves of data generate novel predictions to be tested in subsequent waves - also demonstrated nicely in (House et al., 2013, 2019, 2020) - represent ways in which multiple key insights can be integrated into a unified research question.

Future work on cross-cultural developmental psychology can benefit from capitalizing on the depth of inquiry afforded by detailed ethnographic work and combining it with rigorous and scalable experimental studies which allow for greater breadth of inquiry (points 3 and 7 in Box 1). For this to be a productive union, cross-disciplinary teams are necessary, as are user-friendly standardized protocols that can be easily adapted for different conditions (points 3 and 4 in Box 1). Several recent examples of work blending ethnographic and standardized experimental approaches highlight the utility of combining these approaches. First, Coren Apicella and colleagues (2017) studied risk-seeking behavior in Hadza children using a combination of standardized economic games and observational data on food returns. They then linked sex differences in children's preferences in the economic games to sex differences in their foraging behavior, finding that Hadza males are more risk-seeking than females, even in late childhood. In a second example which further illustrates the utility of cross-disciplinary collaboration, Kajanus and colleagues (2019) conducted a fairness study in two rural schools in China. The team used the Inequity Game, an established task that has been used to measure fairness and its underlying processes across diverse societies (Amir et al., In prep.; Blake et al., 2015; Corbit et al., 2017); see Section 2.2 for more details. A novelty of this study relative to other cross-cultural work that has used the Inequity Game is that it was used to measure fairness in children in conjunction with rich ethnographic information from two schools, further utilizing natural within-country variation (point 6 in Box 1). Ethnographic work suggested these two schools were characterised by distinct sets of norms and values. In the "University School", children received more explicit moral instruction while in the "Community School" children's moral development occurred more in the context of interactions with others. Similarities and differences in children's behaviors were then interpreted 
in the context of this ethnographic information, highlighting the strength of combining standardized tasks and ethnographies.

In sum, the studies above demonstrate promising new directions in developmental science and how the strategies outlined above can be effectively implemented. We believe a greater adoption of these practices can lead to an enriched understanding of child development across diverse contexts.

\section{Concluding Thoughts}

In the decade since Henrich and colleagues' catalytic work on the WEIRD sampling bias (Henrich et al., 2010), behavioral scientists have begun to more closely attend to considerations of culture and context when assessing human behavior. These ripples of change have also reached developmental psychology, within which cross-cultural work is beginning to rise in prominence. Through careful work, we have learned more than ever before about behavioral diversity in early life across differing contexts. Here, we reviewed and discussed two general approaches to cross-cultural, developmental psychology, one favoring breadth of insight and one favoring depth. We presented a historical case study - namely, the Six Cultures study — that fruitfully integrated the strengths of both perspectives and which we hope can inspire future waves of work in a similar fashion. We then reviewed exemplary studies and key insights from the adult literature that can complement the strengths of a combined breadth-depth approach. And lastly, we reviewed promising directions in recent cross-cultural, developmental efforts and summarized key insights in Box 1.

Done carefully, cross-cultural, developmental work can offer important insights into cultural regularities and generate new predictions about the role of the social and ecological environment in shaping behavior. When combined with complementary approaches - such as work with non-human animals and formal modeling - cross-cultural, developmental work can be a powerful tool for better understanding ourselves and our origins. Our goal in this review has been to give readers a tractable overview of how research with children across societies has been conducted in the past, how it can inform our understanding of human evolution, and how it can be integrated with existing methods from the adult literature to produce high-quality, meaningful insights with explanatory depth. We believe these lessons will help move the field of cross-cultural, 
developmental psychology forward, providing new insights into the development, function, and evolution of human behavior.

\section{Acknowledgments}

The authors would like to acknowledge the Canadian Institute for Advanced Research (CIFAR) and the John Templeton Foundation (61138) for their support. They would also like to thank Paul Smaldino, Angie Johnston, Justin Martin, Sheina Lew-Levy, Willem Frankenhuis, Matthew Jordan, and Leo Tiokhin for their helpful feedback and suggestions. 


\section{References}

Ailon, G. (2008). Mirror, mirror on the wall: Culture's consequences in a value test of its own design. Academy of Management Review, 33(4), 885-904.

Allik, J., \& Realo, A. (2004). Individualism-Collectivism and Social Capital. Journal of Cross-Cultural Psychology, 35(1), 29-49. https://doi.org/10.1177/0022022103260381

Alvard, M. S. (2004). The ultimatum game, fairness, and cooperation among big game hunters. Foundations of Human Sociality., 413-435.

https://doi.org/10.1093/0199262055.003.0014

Amir, D., Jordan, M. R., McAuliffe, K., Valeggia, C. R., Sugiyama, L. S., Bribiescas, R. G., Snodgrass, J. J., \& Dunham, Y. (2019). The developmental origins of risk and time preferences across diverse societies. Journal of Experimental Psychology: General, 149(4), 651-661.

Amir, D., Jordan, M. R., \& Rand, D. G. (2018). An uncertainty management perspective on long-run impacts of adversity: The influence of childhood socioeconomic status on risk, time, and social preferences. Journal of Experimental Social Psychology, 79, 217-226. https://doi.org/10.1016/j.jesp.2018.07.014

Amir, D., Valeggia, C., Srinivasan, M., Sugiyama, L. S., \& Dunham, Y. (2019). Measuring subjective social status in children of diverse societies. PloS One, 14(12).

Amir, D., Warneken, F., Peter Blake, Corbit, J., Tara C. Callaghan, Barry, O., Bowie, A., Kleutsch, L., Kramer, K. L., Ross, E., Vongsachang, H., Wrangham, R., \& McAuliffe, K. (In prep.). Beyond choice: Signatures of inequity aversion in children across seven societies.

Apicella, C. L., Crittenden, A. N., \& Tobolsky, V. A. (2017). Hunter-gatherer males are more risk-seeking than females, even in late childhood. Evolution and Human Behavior. 
Arnett, J. J. (2008). The neglected 95\%: Why American psychology needs to become less American. American Psychologist, 63(7), 602.

Austin, C., Smith, T. M., Bradman, A., Hinde, K., Joannes-Boyau, R., Bishop, D., Hare, D. J., Doble, P., Eskenazi, B., \& Arora, M. (2013). Barium distributions in teeth reveal early-life dietary transitions in primates. Nature, 498(7453), 216-219. https://doi.org/10.1038/nature12169

Bandura, A., \& Walters, R. H. (1977). Social Learning Theory (Vol. 1). Prentice-Hall.

Bang, M., \& Medin, D. (2010). Cultural processes in science education: Supporting the navigation of multiple epistemologies. Science Education, 94(6), 1008-1026. https://doi.org/10.1002/sce.20392

Barr, R. G., Konner, M., Bakeman, R., \& Adamson, L. (1991). Crying in !Kung San infants: A test of the cultural specificity hypothesis. Developmental Medicine \& Child Neurology, 33(7), 601-610.

Barrett, H. C., Broesch, T., Scott, R. M., He, Z., Baillargeon, R., Wu, D., Bolz, M., Henrich, J., Setoh, P., \& Wang, J. (2013). Early false-belief understanding in traditional non-Western societies. Proceedings of the Royal Society of London B: Biological Sciences, 280(1755), 20122654.

Barry III, H., Child, I. L., \& Bacon, M. K. (1959). Relation of Child Training to Subsistence Economy. American Anthropologist, 61(1), 51-63.

Bateson, P., Barker, D., Clutton-Brock, T., Deb, D., D’Udine, B., Foley, R. A., Gluckman, P., Godfrey, K., Kirkwood, T., Lahr, M. M., McNamara, J., Metcalfe, N. B., Monaghan, P., Spencer, H. G., \& Sultan, S. E. (2004). Developmental plasticity and human health. Nature, 430(6998), 419-421. https://doi.org/10.1038/nature02725

Benedict, R. (1938). Continuities and discontinuities in cultural conditioning. Psychiatry, 1(2), 
161-167.

Bicchieri, C. (2016). Norms in the wild: How to diagnose, measure, and change social norms. Oxford University Press.

Birch, S. A., Vauthier, S. A., \& Bloom, P. (2008). Three-and four-year-olds spontaneously use others' past performance to guide their learning. Cognition, 107(3), 1018-1034.

Blake, P. R., \& McAuliffe, K. (2011). “I had so much it didn't seem fair”: Eight-year-olds reject two forms of inequity. Cognition, 120(2), 215-224. https://doi.org/10.1016/j.cognition.2011.04.006

Blake, P. R., McAuliffe, K., Corbit, J., Callaghan, T. C., Barry, O., Bowie, A., Kleutsch, L., Kramer, K. L., Ross, E., Vongsachang, H., Wrangham, R., \& Warneken, F. (2015). The ontogeny of fairness in seven societies. Nature, 528(7581), 258-261. https://doi.org/10.1038/nature15703

Boas, F. (1911). Instability of human types. 99-103.

Bochner, S. (1994). Cross-cultural differences in the self concept: A test of Hofstede's individualism/collectivism distinction. Journal of Cross-Cultural Psychology, 25(2), 273-283.

Boden, M. A. (2008). Mind as machine: A history of cognitive science. Oxford University Press. Bornstein, M. H. (2013). Cultural approaches to parenting. Psychology Press.

Bornstein, M. H., Putnick, D. L., Lansford, J. E., Pastorelli, C., Skinner, A. T., Sorbring, E., Tapanya, S., Maria Uribe Tirado, L., Zelli, A., Peña Alampay, L., Al-Hassan, S. M., Bacchini, D., Silvia Bombi, A., Chang, L., Deater-Deckard, K., Di Giunta, L., Dodge, K. A., Malone, P. S., \& Oburu, P. (2015). Mother and Father Socially Desirable Responding in Nine Countries: Two Kinds of Agreement and Relations to Parenting Self-Reports. International Journal of Psychology : Journal International de Psychologie, 50(3), 
174-185. https://doi.org/10.1002/ijop.12084

Bouchouicha, R., \& Vieider, F. M. (2019). Growth, entrepreneurship, and risk-tolerance: A risk-income paradox. Journal of Economic Growth, 24(3), 257-282.

Boyette, A. H., \& Hewlett, B. S. (2017). Autonomy, Equality, and Teaching among Aka Foragers and Ngandu Farmers of the Congo Basin. Human Nature, 28(3), 289-322. https://doi.org/10.1007/s12110-017-9294-y

Brady, L. M., Fryberg, S. A., \& Shoda, Y. (2018). Expanding the interpretive power of psychological science by attending to culture. Proceedings of the National Academy of Sciences, 115(45), 11406-11413. https://doi.org/10.1073/pnas.1803526115

Brase, G. L. (2014). Behavioral science integration: A practical framework of multi-level converging evidence for behavioral science theories. New Ideas in Psychology, 33, 8-20. https://doi.org/10.1016/j.newideapsych.2013.11.001

Bray, F. (1994). The rice economies: Technology and development in Asian societies. University of California Press.

Bronfenbrenner, U. (1994). Ecological models of human development. Readings on the Development of Children, 2(1), 37-43.

Brosseau-Liard, P., Birch, S., \& Chudek, M. (2013). Culture-Gene Coevolutionary Theory and Children's Selective Social Learning. In Navigating the Social World: What Infants, Children, and Other Species Can Teach Us (p. 181). Oxford University Press.

Bruner, J. S., Olver, R. R., \& Greenfield, P. M. (1966). Studies in cognitive growth. Wiley. Callaghan, T., Moll, H., Rakoczy, H., Warneken, F., Liszkowski, U., Behne, T., Tomasello, M., \& Collins, W. A. (2011). Early social cognition in three cultural contexts. Monographs of the Society for Research in Child Development, 76(2).

Callaghan, T., Rochat, P., Lillard, A., Claux, M. L., Odden, H., Itakura, S., Tapanya, S., \& Singh, 
S. (2005). Synchrony in the Onset of Mental-State Reasoning: Evidence from Five Cultures. Psychological Science, 16(5), 378-384.

Carlson, B. A. (2017). Early life experiences have complex and long-lasting effects on behavior. Proceedings of the National Academy of Sciences, 114(44), 11571-11573.

Chisholm, J. S. (1978). Swaddling, cradleboards and the development of children. Early Human Development, 2(3), 255-275.

Chiu Loke, I., Heyman, G. D., Itakura, S., Toriyama, R., \& Lee, K. (2014). Japanese and American children's moral evaluations of reporting on transgressions. Developmental Psychology, 50(5), 1520-1531.

Chudek, M., \& Henrich, J. (2011). Culture-gene coevolution, norm-psychology and the emergence of human prosociality. Trends in Cognitive Sciences, 15(5), 218-226. https://doi.org/10.1016/j.tics.2011.03.003

Clegg, J. M., \& Legare, C. H. (2016). A cross-cultural comparison of children's imitative flexibility. Developmental Psychology, 52(9), 1435.

Cole, M., Gay, J., Glick, J. A., \& Sharp, D. W. (1971). The Cultural Context of Learning and Thinking: An Exploration in Experimental Anthropology. Basic Books.

Corbit, J., McAuliffe, K., Callaghan, T. C., Blake, P. R., \& Warneken, F. (2017). Children's collaboration induces fairness rather than generosity. Cognition, 168, 344-356.

Corsaro, W. A. (1996). Transitions in early childhood: The promise of comparative, longitudinal ethnography. Ethnography and Human Development: Context and Meaning in Social Inquiry, 419-456.

Cowell, J. M., Lee, K., Malcolm-Smith, S., Selcuk, B., Zhou, X., \& Decety, J. (2016). The development of generosity and moral cognition across five cultures. Developmental Science, 20(4), e12403. 
Dasen, P. R. (1972). Cross-Cultural Piagetian Research: A Summary. Journal of Cross-Cultural Psychology, 3(1), 23-40. https://doi.org/10.1177/002202217200300102

Dawson, J. L. (1967). Cultural and Physiological Influences Upon Spatial-Perceptual Processes in West Africa. Part I. International Journal of Psychology, 2(2), 115-128.

de Guzman, M. R., Do, K.-A., \& Kok, C. (2014). The Cultural Contexts of Children's Prosocial Behaviors. Faculty Publications, Department of Child, Youth, and Family Studies. https://digitalcommons.unl.edu/famconfacpub/103

Del Giudice, M., Gangestad, S. W., \& Kaplan, H. S. (2016). Life history theory and evolutionary psychology. In The handbook of evolutionary psychology: Foundations. John Wiley \& Sons Inc.

Deltas, G. (2003). The small-sample bias of the Gini coefficient: Results and implications for empirical research. Review of Economics and Statistics, 85(1), 226-234.

Dennis, W. (1940). The Hopi Child.

Dmytro, D., Lo, J., O’Leary, J., Fu, G., Lee, K., \& Cameron, C. A. (2014). Development of Cultural Perspectives on Verbal Deception in Competitive Contexts. Journal of Cross-Cultural Psychology, 45(8), 1196-1214.

DuBois, C. (1944). The people of Alor; a social-psychological study of an East Indian island. University of Minnesota Press.

Edwards, C. P., \& Whiting, B. (1988). Children of Different Worlds: The Formation of Social Behavior.

Ember, C. R., \& Cunnar, C. M. (2015). Children's play and work: The relevance of cross-cultural ethnographic research for archaeologists. Childhood in the Past, 8(2), 87-103.

Ember, C. R., \& Ember, M. (2005). Explaining corporal punishment of children: A cross-cultural study. American Anthropologist, 107(4), 609-619. 
Ensminger, J. (2004). Market integration and fairness: Evidence from ultimatum, dictator, and public goods experiments in East Africa. Foundations of Human Sociality: Economic Experiments and Ethnographic Evidence from Fifteen Small-Scale Societies, 356-381.

Farrell, S., \& Lewandowsky, S. (2018, February). Computational Modeling of Cognition and Behavior. Cambridge Core. https://doi.org/10.1017/CBO9781316272503

Fawcett, T. W., \& Frankenhuis, W. E. (2015). Adaptive explanations for sensitive windows in development. Frontiers in Zoology, 12(1), S3.

Fehr, E., Bernhard, H., \& Rockenbach, B. (2008). Egalitarianism in young children. Nature, 454(7208), 1079.

Fleeson, W. (2001). Toward a structure-and process-integrated view of personality: Traits as density distributions of states. Journal of Personality and Social Psychology, 80(6), 1011.

Fodor, J. A. (2001). The mind doesn't work that way: The scope and limits of computational psychology. MIT press.

Fortes, M. (1938). Social and psychological aspects of education in Taleland. Oxford University Press London.

Fowler, J. H., Johnson, T., \& Smirnov, O. (2005). Egalitarian motive and altruistic punishment. Nature, 433(7021), E1-E1. https://doi.org/10.1038/nature03256

Frank, M. C., Bergelson, E., Bergmann, C., Cristia, A., Floccia, C., Gervain, J., Hamlin, J. K., Hannon, E. E., Kline, M., Levelt, C., Lew-Williams, C., Nazzi, T., Panneton, R., Rabagliati, H., Soderstrom, M., Sullivan, J., Waxman, S., \& Yurovsky, D. (2017). A Collaborative Approach to Infant Research: Promoting Reproducibility, Best Practices, and Theory-Building. Infancy, 22(4), 421-435. https://doi.org/10.1111/infa.12182

Frankenhuis, W. E., \& Del Giudice, M. (2012). When do adaptive developmental mechanisms yield maladaptive outcomes? Developmental Psychology, 48(3), 628-628. 
Frankenhuis, W. E., \& Fraley, R. C. (2016). What Do Evolutionary Models Teach Us About Sensitive Periods in Psychological Development? European Psychologist.

Frankenhuis, W. E., Nettle, D., \& Dall, S. R. X. (2019). A case for environmental statistics of early-life effects. Philosophical Transactions of the Royal Society B: Biological Sciences, 374(1770). https://doi.org/10.1098/rstb.2018.0110

Frankenhuis, W. E., \& Panchanathan, K. (2011). Balancing sampling and specialization: An adaptationist model of incremental development. Proceedings of the Royal Society B: Biological Sciences, 278(1724), 3558-3565. https://doi.org/10.1098/rspb.2011.0055

Frankenhuis, W. E., Panchanathan, K., \& Barrett, H. C. (2013). Bridging developmental systems theory and evolutionary psychology using dynamic optimization. Developmental Science, 16(4), 584-598.

Frankenhuis, W. E., Panchanathan, K., \& Nettle, D. (2016). Cognition in harsh and unpredictable environments. Current Opinion in Psychology, 7, 76-80. https://doi.org/10.1016/j.copsyc.2015.08.011

Frankenhuis, W. E., \& Tiokhin, L. (2018). Bridging evolutionary biology and developmental psychology: Toward an enduring theoretical infrastructure. Child Development, 89(6), 2303-2306.

Frankenhuis, W. E., \& Walasek, N. (2020). Modeling the evolution of sensitive periods. Developmental Cognitive Neuroscience, 41, 100715. https://doi.org/10.1016/j.den.2019.100715

Galizzi, M. M., \& Navarro-Martinez, D. (2018). On the External Validity of Social Preference Games: A Systematic Lab-Field Study. Management Science, 65(3), 976-1002. https://doi.org/10.1287/mnsc.2017.2908

Gaskins, S. (2000). Children's daily activities in a Mayan village: A culturally grounded 
description. Cross-Cultural Research, 34(4), 375-389.

Genyue, F., Heyman, G. D., \& Lee, K. (2011). Reasoning about modesty among adolescents and adults in China and the US. Journal of Adolescence, 34(4), 599-608.

Gibbons, A. (2008). The birth of childhood. Science, 322(5904), 1040-1043.

Greenfield, P. M. (2009). Linking social change and developmental change: Shifting pathways of human development. Developmental Psychology, 45(2), 401.

Greenfield, P. M., Keller, H., Fuligni, A., \& Maynard, A. (2003). Cultural Pathways Through Universal Development. Annual Review of Psychology, 54(1), 461-490.

Gurven, M. (2018). Broadening horizons: Sample diversity and socioecological theory are essential to the future of psychological science. Proceedings of the National Academy of Sciences, 115(45), 11420-11427.

Gurven, M., Von Rueden, C., Massenkoff, M., Kaplan, H., \& Lero Vie, M. (2013). How universal is the Big Five? Testing the five-factor model of personality variation among forager-farmers in the Bolivian Amazon. Journal of Personality and Social Psychology, 104(2), 354.

Gurven, M., \& Winking, J. (2008). Collective Action in Action: Prosocial Behavior in and out of the Laboratory. American Anthropologist, 110(2), 179-190. https://doi.org/10.1111/j.1548-1433.2008.00024.x

Handley, C., \& Mathew, S. (2020). Human large-scale cooperation as a product of competition between cultural groups. Nature Communications, 11(1), 1-9. https://doi.org/10.1038/s41467-020-14416-8

Hardisty, D. J., Thompson, K. F., Krantz, D. H., \& Weber, E. U. (2013). How to measure time preferences: An experimental comparison of three methods. Judgment \& Decision Making, 8(3). 
Harkness, S., \& Super, C. M. (1994). The developmental niche: A theoretical framework for analyzing the household production of health. Social Science \& Medicine, 38(2), 217-226.

Hawkes, K., O’Connell, F., \& Jones, N. B. (1995). Hadza children's foraging: Juvenile dependency, social arrangements, and mobility among hunter-gatherers. Current Anthropology, 36(4), 688-700.

Henrich, J., Boyd, R., Bowles, S., Camerer, C., Fehr, E., Gintis, H., \& McElreath, R. (2001). In search of homo economicus: Behavioral experiments in 15 small-scale societies. American Economic Review, 91(2), 73-78.

Henrich, J., Boyd, R., Bowles, S., Camerer, C., Fehr, E., Gintis, H., McElreath, R., Alvard, M., Barr, A., \& Ensminger, J. (2005). "Economic man” in cross-cultural perspective: Behavioral experiments in 15 small-scale societies. Behavioral and Brain Sciences, 28(6), 795-815.

Henrich, J., Heine, S. J., \& Norenzayan, A. (2010). The weirdest people in the world? Behav Brain Sci, 33(2-3), 61-135. https://doi.org/10.1017/S0140525X0999152X

Henrich, J., McElreath, R., Barr, A., Ensminger, J., Barrett, C., Bolyanatz, A., Cardenas, J. C., Gurven, M., Gwako, E., \& Henrich, N. (2006). Costly punishment across human societies. Science, 312(5781), 1767-1770.

Heyman, G. D., Itakura, S., \& Lee, K. (2010). Japanese and American Children's Reasoning about Accepting Credit for Prosocial Behavior. Social Development, 20(1), 171-184.

Hill, K., \& Gurven, M. (2004). Economic experiments to examine fairness and cooperation among the Ache Indians of Paraguay. Foundations in Human Sociality: Economic Experiments and Ethnographic Evidence from Fifteen Small-Scale Societies, 382-412.

Hinton, G. E., \& Nowlan, S. J. (1987). How learning can guide evolution. Complex Systems, 
1(3), 495-502.

Hirschfeld, L. A. (2002). Why Don't Anthropologists Like Children? American Anthropologist, 104(2), 611-627. https://doi.org/10.1525/aa.2002.104.2.611

Hofstede, G. (1984). Culture's consequences: International differences in work-related values (Vol. 5). sage.

Hofstede, G. (2011). Dimensionalizing cultures: The Hofstede model in context. Online Readings in Psychology and Culture, 2(1), 8.

Hogbin, H. I. (1946). A New Guinea childhood: From weaning till the eighth year in Wogeo. Oceania, 16(4), 275-296.

Hong, J. S., \& Espelage, D. L. (2012). A review of research on bullying and peer victimization in school: An ecological system analysis. Aggression and Violent Behavior, 17(4), $311-322$.

House, B. R., Kanngiesser, P., Barrett, H. C., Broesch, T., Cebioglu, S., Crittenden, A. N., Erut, A., Lew-Levy, S., Sebastian-Enesco, C., Smith, A. M., Yilmaz, S., \& Silk, J. B. (2019). Universal norm psychology leads to societal diversity in prosocial behaviour and development. Nature Human Behaviour, 1-11.

House, B. R., Kanngiesser, P., Barrett, H. C., Yilmaz, S., Smith, A. M., Sebastian-Enesco, C., Erut, A., \& Silk, J. B. (2020). Social norms and cultural diversity in the development of third-party punishment. Proceedings of the Royal Society B: Biological Sciences, 287(1925), 20192794. https://doi.org/10.1098/rspb.2019.2794

House, B. R., Silk, J. B., Henrich, J., Barrett, H. C., Scelza, B. A., Boyette, A. H., Hewlett, B. S., McEIreath, R., \& Laurence, S. (2013). Ontogeny of prosocial behavior across diverse societies. Proceedings of the National Academy of Sciences, 110(36), 14586-14591.

Huppert, E., Cowell, J. M., Cheng, Y., Contreras-Ibáñez, C., Gomez-Sicard, N., 
Gonzalez-Gaeda, L. M., Huepe, D., Ibanez, A., Lee, K., Mahasneh, R., Malcolm-Smith, S., Salas, N., Selcuk, B., Tungodden, B., Wong, A., Zhou, X., \& Decety, J. (2018). The development of children's preferences for equality and equity across 13 individualistic and collectivist cultures. Developmental Science, e12729.

https://doi.org/10.1111/desc.12729

John, O. P., Naumann, L. P., \& Soto, C. J. (2008). Paradigm shift to the integrative big five trait taxonomy. Handbook of Personality: Theory and Research, 3(2), 114-158.

Kajanus, A., McAuliffe, K., Warneken, F., \& Blake, P. R. (2019). Children's fairness in two Chinese schools: A combined ethnographic and experimental study. Journal of Experimental Child Psychology, 177, 282-296.

Kaplan, H., \& Dove, H. (1987). Infant development among the Ache of eastern Paraguay. Developmental Psychology, 23(2), 190.

Kardiner, A. (1939). The individual and his society: The psychodynamics of primitive social organization.

Kardiner, A., Linton, R., Du Bois, C., \& West, J. (1945). The psychological frontiers of society. Keller, H. (2007). Cultures of infancy. Routledge.

Keller, H. (2010). Linkages between the whiting model and contemporary evolutionary theory. Journal of Cross-Cultural Psychology, 41(4), 563-577.

Keller, H. (2018). Universality claim of attachment theory: Children's socioemotional development across cultures. Proceedings of the National Academy of Sciences, 115(45), 11414-11419.

Kerr, W. R. (2014). Income inequality and social preferences for redistribution and compensation differentials. Journal of Monetary Economics, 66, 62-78.

Kievit, R., Frankenhuis, W. E., Waldorp, L., \& Borsboom, D. (2013). Simpson's paradox in 
psychological science: A practical guide. Frontiers in Psychology, 4, 513.

Killen, M., \& Wainryb, C. (2000). Independence and interdependence in diverse cultural contexts. New Directions for Child and Adolescent Development, 2000(87), 5-21.

Kitayama, S. (2002). Culture and basic psychological processes--Toward a system view of culture: Comment on Oyserman et al. (2002). Psychological Bulletin, 128(1), 89-96. https://doi.org/10.1037/0033-2909.128.1.89

Konner, M. (1972). Aspects of the developmental ethology of a foraging people. Ethological Studies of Child Behaviour, 285-304.

Konner, M. (1976). Maternal care, infant behavior and development among the! Kung. In Kalahari hunter-gatherers: Studies of the !Kung San and their neighbors. Harvard University Press.

Konner, M. (2005). Hunter-gatherer infancy and childhood: The !Kung and others. In Hunter-Gatherer Childhoods: Evolutionary, Developmental, and Cultural Perspectives (pp. 19-64). Routledge.

Konner, M. (2010). The evolution of childhood: Relationships, emotion, mind. Harvard University Press.

Krassner, A. M., Gartstein, M. A., Park, C., Dragan, W. Ł., Lecannelier, F., \& Putnam, S. P. (2016). East-west, collectivist-individualist: A cross-cultural examination of temperament in toddlers from Chile, Poland, South Korea, and the U.S. European Journal of Developmental Psychology, 14(4), 449-464.

Kröll, M., \& Rustagi, D. (2017). Reputation, honesty, and cheating in informal milk markets in India. SAFE Working Paper.

Kruger, A. C., \& Tomasello, M. (1996). Cultural learning and learning culture. The Handbook of Education and Human Development, 369-387. 
Kuijper, B., Hanson, M. A., Vitikainen, E. I. K., Marshall, H. H., Ozanne, S. E., \& Cant, M. A. (2019). Developing differences: Early-life effects and evolutionary medicine. Philosophical Transactions of the Royal Society B: Biological Sciences, 374(1770), 20190039. https://doi.org/10.1098/rstb.2019.0039

Lamba, S., \& Mace, R. (2011). Demography and ecology drive variation in cooperation across human populations. Proceedings of the National Academy of Sciences, 108(35), 14426-14430. https://doi.org/10.1073/pnas.1105186108

Lancy, D. F., Bock, J., \& Gaskins, S. (2010). The anthropology of learning in childhood. Rowman Altamira.

Lee, K., Cameron, C. A., Xu, F., And, G. F., \& Board, J. (1997). Chinese and Canadian Children's Evaluations of Lying and Truth Telling: Similarities and Differences in the Context of pro-and Antisocial Behaviors. Child Development, 68(5), 924-934.

Lee, K., Xu, F., Fu, G., Cameron, C. A., \& Chen, S. (2001). Taiwan and Mainland Chinese and Canadian children's categorization and evaluation of lie-and truth-telling: A modesty effect. British Journal of Developmental Psychology, 19(4), 525-542.

Lee, R. D., \& Kramer, K. L. (2002). Children's economic roles in the Maya family life cycle: Cain, Caldwell, and Chayanov revisited. Population and Development Review, 28(3), 475-499.

Legare, C. H., \& Harris, P. L. (2016). The Ontogeny of Cultural Learning. Child Development, 87(3), 633-642. https://doi.org/10.1111/cdev.12542

Legare, C. H., \& Nielsen, M. (2015). Imitation and innovation: The dual engines of cultural learning. Trends in Cognitive Sciences, 19(11), 688-699.

Legare, C. H., Wen, N. J., Herrmann, P. A., \& Whitehouse, H. (2015). Imitative flexibility and the development of cultural learning. Cognition, 142, 351-361. 
Leighton, D. C., \& Kluckhohn, C. (1947). Children of the People.

LeVine, R. (2007). Ethnographic studies of childhood: A historical overview. American Anthropologist, 109(2), 247-260.

LeVine, R. (2010). The six cultures study: Prologue to a history of a landmark project. Journal of Cross-Cultural Psychology, 41(4), 513-521.

LeVine, R., New, R. S., \& Wiley, J. (2008). Anthropology and child development: A cross-cultural reader. Blackwell Pub.

Levinson, D. (1989). The human relations area files. Reference Services Review, 17(3), 83-90.

Levitt, S. D., \& List, J. A. (2007). What Do Laboratory Experiments Measuring Social Preferences Reveal About the Real World? Journal of Economic Perspectives, 21(2), 153-174. https://doi.org/10.1257/jep.21.2.153

Lew-Levy, S., Reckin, R., Lavi, N., Cristóbal-Azkarate, J., \& Ellis-Davies, K. (2017). How do hunter-gatherer children learn subsistence skills? Human Nature, 28(4), 367-394.

Liebal, K., \& Haun, D. B. M. (2018). Why cross-cultural psychology is incomplete without comparative and developmental perspectives. Journal of Cross-Cultural Psychology, 49(5), 751-763.

Lowes, S., Nunn, N., Robinson, J. A., \& Weigel, J. L. (2017). The evolution of culture and institutions: Evidence from the Kuba kingdom. Econometrica, 85(4), 1065-1091.

Malinowski, B. (1929). The sexual life of savages in northwestern Melanesia. Liveright.

Mareschal, D., \& Thomas, M. S. (2007). Computational modeling in developmental psychology. IEEE Transactions on Evolutionary Computation, 11(2), 137-150.

Markus, H. R., \& Kitayama, S. (2010). Cultures and selves: A cycle of mutual constitution. Perspectives on Psychological Science, 5(4), 420-430.

McAuliffe, K., \& Santos, L. R. (2018). Do Animals Have a Sense of Fairness? Atlas of Moral 
Psychology, 393.

McCrae, R. R., \& Costa Jr, P. T. (1997). Personality trait structure as a human universal. American Psychologist, 52(5), 509.

McSweeney, B. (2002). Hofstede's model of national cultural differences and their consequences: A triumph of faith-a failure of analysis. Human Relations, 55(1), 89-118.

Mead, M. (1928). Coming of Age in Samoa: A Study of Sex in Primitive Society.

Miller, P. J., \& Goodnow, J. J. (1995). Cultural practices: Toward an integration of culture and development.

Minturn, L., \& Lambert, W. W. (1964). Mothers of six cultures.

Munroe, R. L., \& Gauvain, M. (2010). The cross-cultural study of children's learning and socialization: A short history. In The Anthropology of Learning in Childhood (p. 35). Rowman \& Littlefield.

Muthukrishna, M., Bell, A. V., Henrich, J., Curtin, C. M., Gedranovich, A., McInerney, J., \& Thue, B. (2020). Beyond Western, Educated, Industrial, Rich, and Democratic (WEIRD) Psychology: Measuring and Mapping Scales of Cultural and Psychological Distance. Psychological Science, 095679762091678. https://doi.org/10.1177/0956797620916782

Muthukrishna, M., \& Henrich, J. (2019). A problem in theory. Nature Human Behaviour, 3(3), 221-229. https://doi.org/10.1038/s41562-018-0522-1

Neldner, K., Redshaw, J., Murphy, S., Tomaselli, K., Davis, J., Dixson, B., \& Nielsen, M. (2019). Creation across culture: Children's tool innovation is influenced by cultural and developmental factors. Developmental Psychology, 55(4), 877-889. https://doi.org/10.1037/dev0000672

Nettle, D., Coall, D. A., \& Dickins, T. E. (2011). Early-life conditions and age at first pregnancy in British women. Proceedings of the Royal Society B: Biological Sciences, 278(1712), 
1721-1727. https://doi.org/10.1098/rspb.2010.1726

Nettle, D., Colléony, A., \& Cockerill, M. (2011). Variation in cooperative behaviour within a single city. PloS One, 6(10).

Nettle, D., Frankenhuis, W. E., \& Rickard, I. J. (2013). The evolution of predictive adaptive responses in human life history. Proceedings of the Royal Society of London B:

Biological Sciences, 280(1766), 20131343-20131343.

Nielsen, M., \& Haun, D. (2016). Why developmental psychology is incomplete without comparative and cross-cultural perspectives. Philosophical Transactions of the Royal Society B: Biological Sciences, 371(1686), 20150071.

Nielsen, M., Haun, D., Kärtner, J., \& Legare, C. H. (2017). The persistent sampling bias in developmental psychology: A call to action. Journal of Experimental Child Psychology, 162, 31-38. https://doi.org/10.1016/j.jecp.2017.04.017

Norenzayan, A., \& Heine, S. J. (2005). Psychological universals: What are they and how can we know? Psychological Bulletin, 131(5), 763.

Nunn, N. (2009). The importance of history for economic development. Annu. Rev. Econ., 1(1), $65-92$.

Parmar, P., Harkness, S., \& Super, C. M. (2004). Asian and Euro-American parents' ethnotheories of play and learning: Effects on preschool children's home routines and school behaviour. International Journal of Behavioral Development, 28(2), 97-104. https://doi.org/10.1080/01650250344000307

Pepper, G. V., \& Nettle, D. (2017). The behavioural constellation of deprivation: Causes and consequences. The Behavioral and Brain Sciences, 1-1.

Piff, P. K., Kraus, M. W., Côté, S., Cheng, B. H., \& Keltner, D. (2010). Having less, giving more: The influence of social class on prosocial behavior. Journal of Personality and Social 
Psychology, 99(5), 771-771.

Pinker, S. (2005). So how does the mind work? Mind \& Language, 20(1), 1-24.

Pollet, T. V., Tybur, J. M., Frankenhuis, W. E., \& Rickard, I. J. (2014). What Can Cross-Cultural Correlations Teach Us about Human Nature? Human Nature, 25(3), 410-429. https://doi.org/10.1007/s12110-014-9206-3

Pope Edwards, C., \& Bloch, M. (2010). The Whitings' concepts of culture and how they have fared in contemporary psychology and anthropology. Journal of Cross-Cultural Psychology, 41(4), 485-498.

Price-Williams, D., Gordon, W., \& Ramirez, M. (1969). Skill and conservation: A study of pottery-making children. Developmental Psychology, 1(6p1), 769.

Rad, M. S., Martingano, A. J., \& Ginges, J. (2018). Toward a psychology of Homo sapiens: Making psychological science more representative of the human population. Proceedings of the National Academy of Sciences, 115(45), 11401-11405. https://doi.org/10.1073/pnas.1721165115

Rakoczy, H., Hamann, K., Warneken, F., \& Tomasello, M. (2010). Bigger knows better: Young children selectively learn rule games from adults rather than from peers. British Journal of Developmental Psychology, 28(4), 785-798.

Raymond, F. (1936). We, the Tikopia. London, Georges Allen and Unwin.

Reali, F., Chater, N., \& Christiansen, M. H. (2018). Simpler grammar, larger vocabulary: How population size affects language. Proceedings of the Royal Society B: Biological Sciences, 285(1871), 20172586.

Realo, A., \& Allik, J. (2002). The nature and scope of intra-cultural variation on psychological dimensions. Online Readings in Psychology and Culture, 2(2), 4.

Richerson, P. J., \& Boyd, R. (2005). Not by genes alone: How culture transformed human 
evolution. Not by Genes Alone: How Culture Transformed Human Evolution., ix, 332-ix, 332.

Rochat, P., Dias, M. D. G., Guo, L., Broesch, T., Passos-Ferreira, C., Winning, A., \& Berg, B. (2009). Fairness in Distributive Justice by 3- and 5-Year-Olds Across Seven Cultures. Journal of Cross-Cultural Psychology, 40(3), 416-442.

Rochat, P., Dias, M. D. G., Guo Liping, Broesch, T., Passos-Ferreira, C., Winning, A., \& Berg, B. (2009). Fairness in Distributive Justice by 3- and 5-Year-Olds Across Seven Cultures. Journal of Cross-Cultural Psychology, 40(3), 416-442. https://doi.org/10.1177/0022022109332844

Rochat, P., Robbins, E., Passos-Ferreira, C., Oliva, A. D., Dias, M. D. G., \& Guo, L. (2014). Ownership reasoning in children across cultures. Cognition, 132(3), 471-484.

Rogoff, B. (1990). Apprenticeship in thinking: Cognitive development in social context. Oxford university press.

Rogoff, B. (2003). The cultural nature of human development. Oxford university press.

Rogoff, B., Sellers, M. J., Pirrotta, S., Fox, N., \& White, S. H. (1975). Age of assignment of roles and responsibilities to children. Human Development, 18(5), 353-369.

Roheim, G. (1936). Psychoanalysis of Primitive Cultural Types. The Journal of Nervous and Mental Disease, 83(4), 475.

Rohner, R. P. (1975). They love me, they love me not: A worldwide study of the effects of parental acceptance and rejection.

Rosenthal, T. L., \& Zimmerman, B. J. (1978). Social learning and cognition. Academic Press.

Rowley, S. J., \& Camacho, T. C. (2015). Increasing diversity in cognitive developmental research: Issues and solutions. Journal of Cognition and Development, 16(5), 683-692.

Safra, L., Tecu, T., Lambert, S., Sheskin, M., Baumard, N., \& Chevallier, C. (2016). 
Neighborhood Deprivation Negatively Impacts Children's Prosocial Behavior. Frontiers in Psychology, 7. https://doi.org/10.3389/fpsyg.2016.01760

Salali, G. D., Chaudhary, N., Bouer, J., Thompson, J., Vinicius, L., \& Migliano, A. B. (2019). Development of social learning and play in BaYaka hunter-gatherers of congo. Scientific Reports, 9(1), 1-10.

Salali, G. D., \& Migliano, A. B. (2015). Future Discounting in Congo Basin Hunter-Gatherers Declines with Socio-Economic Transitions. PLoS One, 10(9), e0137806-e0137806.

Schäfer, M., Haun, D. B. M., \& Tomasello, M. (2015). Fair Is Not Fair Everywhere. Psychological Science : A Journal of the American Psychological Society / APS, 26(8), 1252-1260.

Schulz, J. F., Bahrami-Rad, D., Beauchamp, J. P., \& Henrich, J. (2019). The Church, intensive kinship, and global psychological variation. Science, 366(6466). https://doi.org/10.1126/science.aau5141

Scott-Phillips, T. C., Dickins, T. E., \& West, S. A. (2011). Evolutionary theory and the ultimate-proximate distinction in the human behavioral sciences. Perspectives on Psychological Science, 6(1), 38-47.

Shultz, T. R. (2003). Computational developmental psychology. Mit Press.

Shweder, R. A. (1999). Why Cultural Psychology? Ethos, 27(1), 62-73. https://doi.org/10.1525/eth.1999.27.1.62

Singh, J. P. (1990). Managerial Culture and Work-related Values in India. Organization Studies, 11(1), 075-101. https://doi.org/10.1177/017084069001100106

Smaldino, P. E. (2017). Models are stupid, and we need more of them. In Computational social psychology (pp. 311-331). Routledge.

Smaldino, P. E. (2019). Better methods can't make up for mediocre theory. Nature, 575(7781), 9. https://doi.org/10.1038/d41586-019-03350-5 
Smaldino, P. E., Lukaszewski, A., von Rueden, C., \& Gurven, M. (2019). Niche diversity can explain cross-cultural differences in personality structure. Nature Human Behaviour, 1-8.

Sobel, D. M., \& Corriveau, K. H. (2010). Children monitor individuals' expertise for word learning. Child Development, 81(2), 669-679.

Stamps, J. A., \& Frankenhuis, W. E. (2016). Bayesian Models of Development. Trends in Ecology \& Evolution, 31(4), 260-268. https://doi.org/10.1016/j.tree.2016.01.012

Super, C. M., \& Harkness, S. (1986). The developmental niche: A conceptualization at the interface of child and culture. International Journal of Behavioral Development, 9(4), $545-569$.

Super, C. M., Harkness, S., Van Tijen, N., Van Der Vlugt, E., Fintelman, M., \& Dijkstra, J. (1996). The three R's of Dutch childrearing and the socialization of infant arousal. Parents' Cultural Belief Systems: Their Origins, Expressions, and Consequences, 447-466.

Talhelm, T., Zhang, X., Oishi, S., Shimin, C., Duan, D., Lan, X., \& Kitayama, S. (2014). Large-scale psychological differences within China explained by rice versus wheat agriculture. Science, 344(6184), 603-608.

Thompson, C., Barresi, J., \& Moore, C. (1997). The development of future-oriented prudence and altruism in preschoolers. Cognitive Development, 12(2), 199-212.

Tinbergen, N. (1963). On aims and methods of ethology. Ethology, 20(4), 410-433.

Trommsdorff, G., \& Kornadt, H.-J. (2003). Parent-child relations in cross-cultural perspective. Handbook of Dynamics in Parent-Child Relations, 271-306.

Tronick, E. Z., Morelli, G. A., \& Winn, S. (1987). Multiple caretaking of Efe (Pygmy) infants. American Anthropologist, 89(1), 96-106.

Turchin, P., Currie, T. E., Turner, E. A., \& Gavrilets, S. (2013). War, space, and the evolution of 
Old World complex societies. Proceedings of the National Academy of Sciences, 110(41), 16384-16389.

van Leeuwen, E. J. C., Cohen, E., Collier-Baker, E., Rapold, C. J., Schäfer, M., Schütte, S., \& Haun, D. B. M. (2018). The development of human social learning across seven societies. Nature Communications, 9(1). https://doi.org/10.1038/s41467-018-04468-2

Vélez-Agosto, N. M., Soto-Crespo, J. G., Vizcarrondo-Oppenheimer, M., Vega-Molina, S., \& García Coll, C. (2017). Bronfenbrenner's bioecological theory revision: Moving culture from the macro into the micro. Perspectives on Psychological Science, 12(5), 900-910.

Vygotsky, L. S. (1980). Mind in society: The development of higher psychological processes. Harvard university press.

Wang, M., Rieger, M. O., \& Hens, T. (2016). How time preferences differ: Evidence from 53 countries. Journal of Economic Psychology, 52, 115-135.

Waterman, A. H., \& Blades, M. (2011). Helping children correctly say “I don’t know” to unanswerable questions. Journal of Experimental Psychology: Applied, 17(4), 396-405. https://doi.org/10.1037/a0026150

Wedgwood, C. H. (1938). The life of children in Manam. Oceania, 9(1), 1-29.

Weisner, T. S. (2002). Ecocultural understanding of children's developmental pathways. Human Development, 45(4), 275-281.

Weisner, T. S., Gallimore, R., Bacon, M. K., Barry, Herbert, Bell, C., Novaes, S. C., Edwards, C. P., Goswami, B. B., Minturn, L., Nerlove, S. B., Koel, A., Ritchie, J. E., Rosenblatt, P. C., Singh, T. R., Sutton-Smith, B., Whiting, B. B., Wilder, W. D., \& Williams, T. R. (1977). My Brother's Keeper: Child and Sibling Caretaking [and Comments and Reply]. Current Anthropology, 18(2), 169-190. https://doi.org/10.1086/201883

West-Eberhard, M. J. (2003). Developmental plasticity and evolution. Oxford University Press. 
Whiting, B. B. (1963). Six cultures: Studies of child rearing.

Whiting, B. B., \& Whiting, J. W. (1975). Children of six cultures: A psycho-cultural analysis.

Whiting, J. (1977). A model for psychocultural research. Culture and Infancy: Variations in the Human Experience, 29-48.

Whiting, J. W., \& Child, I. L. (1953). Child training and personality: A cross-cultural study.

Wood, D., \& Denissen, J. J. (2014). A functional perspective on personality trait development. In Psychology of Change (pp. 111-129). Psychology Press.

Worthman, C. M. (2010). The ecology of human development: Evolving models for cultural psychology. Journal of Cross-Cultural Psychology, 41(4), 546-562. 